Engineer Research and

Development Center

Engineering for Polar Operations, Logistics, and Research (EPOLAR)

\title{
Feasibility of Using Alternate Fuels in the U.S. Antarctic Program
}

Initial Assessment

Robert B. Haehnel, Terry Melendy, and George L. Blaisdell

September 2017

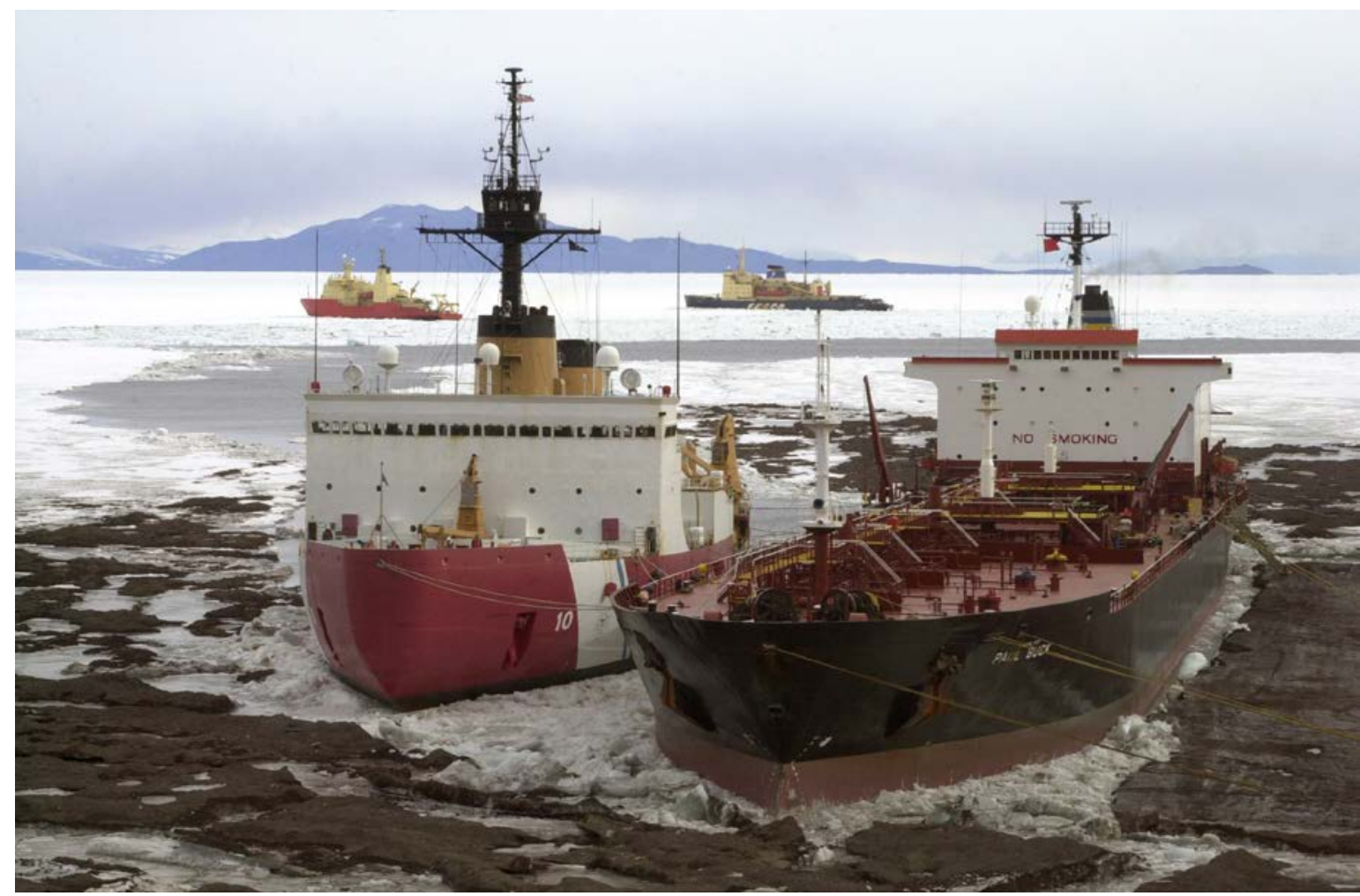


The U.S. Army Engineer Research and Development Center (ERDC) solves the nation's toughest engineering and environmental challenges. ERDC develops innovative solutions in civil and military engineering, geospatial sciences, water resources, and environmental sciences for the Army, the Department of Defense, civilian agencies, and our nation's public good. Find out more at www.erdc.usace.army.mil.

To search for other technical reports published by ERDC, visit the ERDC online library at http://acwc.sdp.sirsi.net/client/default.

Cover Image: USNS Paul Buck, an ice-reinforced fuel tanker, docks at McMurdo's ice pier with the assistance of the U.S. Coast Guard icebreaker Polar Star. Paul Buck will supply McMurdo with over six million gallons of fuel, in three types, to provide a year's worth of fuel for everything from space heaters and snowmobiles to the power plants at McMurdo and South Pole Stations and all aircraft and heavy equipment. In the background, Far East Shipping Company's icebreaker Krasin and the U.S. Antarctic Program's research vessel Nathaniel B. Palmer await opportunities to come alongside and directly refuel. Photo courtesy of the National Science Foundation. 


\section{Feasibility of Using Alternate Fuels in the U.S. Antarctic Program}

Initial Assessment

Robert B. Haehnel, Terry Melendy, and George L. Blaisdell

U.S. Army Engineer Research and Development Center (ERDC)

Cold Regions Research and Engineering Laboratory (CRREL)

72 Lyme Road

Hanover, NH 03755-1290

Final Report

Approved for public release; distribution is unlimited.

Prepared for National Science Foundation, Office of Polar Programs,

Arlington, VA 22230

Under Engineering for Polar Operations, Logistics, and Research (EPOLAR) EP-ANT-14-23, "Antarctic Fuel Options" 


\section{Abstract}

Currently, the U.S. Antarctic Program (USAP) has standardized using AN8 fuel for all air operations and the majority of its ground based operations. The freeze-point (FP) specification for AN8 is $-58^{\circ} \mathrm{C}$. The U.S. Army Cold Regions Research and Engineering Laboratory (CRREL) conducted an analysis of the air temperature history at McMurdo, South Pole, and the WAIS (West Antarctic Ice Sheet) Divide camp to determine if USAP could feasibly use alternate, less expensive aircraft fuels. Also, to provide context, this report details the USAP fuel purchasing methodology and price calculation.

JP-8 (and J et A-1) has an FP specification of $-47^{\circ} \mathrm{C}$, which is well below the minimum average daily air temperature at McMurdo $\left(-40^{\circ} \mathrm{C}\right)$ and is also below the storage temperature of the fuel at South Pole $\left(-45^{\circ} \mathrm{C}\right)$. The estimated fuel temperature at the WAIS Divide camp is above the FP of J P-8 during the operational season. Based on these findings, it may be possible to use J P-8 to replace ground-based applications where AN8 is currently used. Evidence suggests that J P-8 can replace the AN8 used for all flight operations, also.

DISCLAIMER: The contents of this report are not to be used for advertising, publication, or promotional purposes. Citation of trade names does not constitute an official endorsement or approval of the use of such commercial products. All product names and trademarks cited are the property of their respective owners. The findings of this report are not to be construed as an official Department of the Army position unless so designated by other authorized documents. 


\section{Contents}

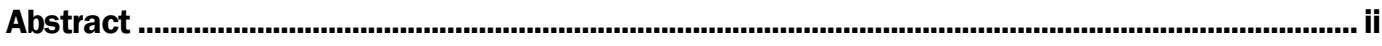

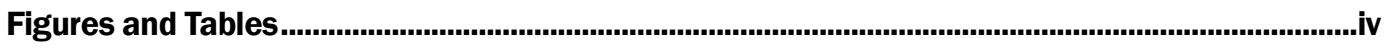

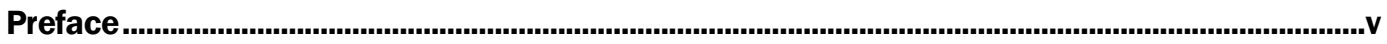
Acronyms and Abbreviations .......................................................................................................
Unit Conversion Factors ................................................................................................................... vifi

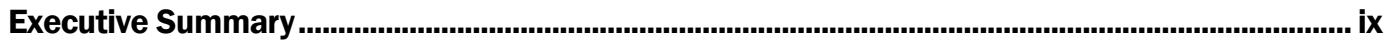

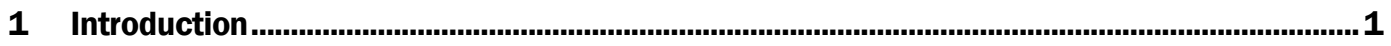

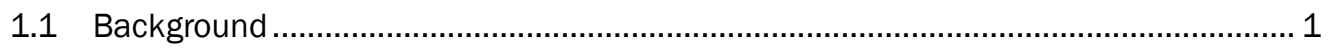

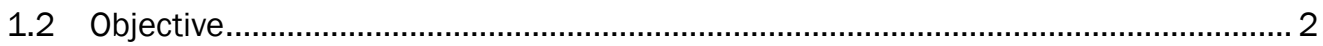

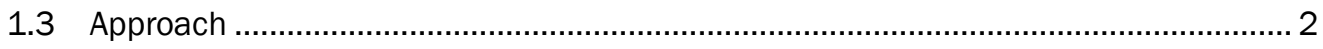

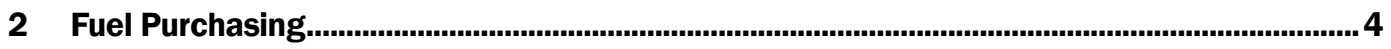

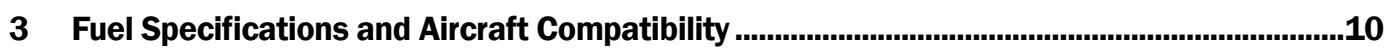

3.1 Low-temperature performance of fuels........................................................... 12

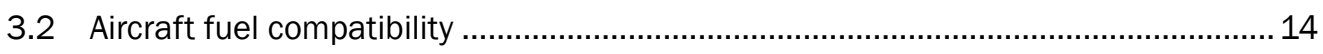

4 Fuel Compatibility for Ground-Based Applications .............................................................15

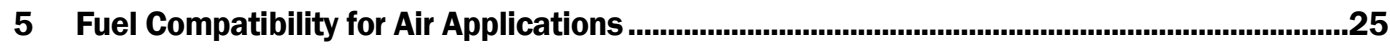

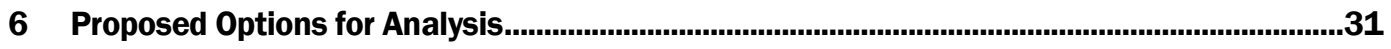

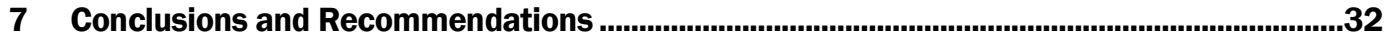

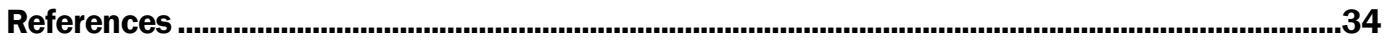

Appendix A: Estimate of Temperature Data for WAIS Divide Camp Using Data from

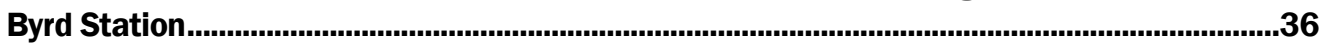

Report Documentation Page 


\section{Figures and Tables}

\section{Figures}

1 Platts' Jet A fuel prices per gallons from 1990 to 2013. Platts' pricing is a real time market process for determining the cost of fossil fuels. This process takes into account supply, demand, and current events. Since 1909, Platts has been reporting these real time prices and benchmark price assessments (Platts 2017) ............ 2

2 Estimated AN8 fuel cost comparison for all months over a 9-year period based on the Platts' pricing for aviation fuel from 2005 to 2013.

3 AN8 fuel cost comparison for December and January when purchasing six million gallons

4 Comparison of statistics of the observed air temperature at McMurdo, Antarctica, to the FP specification for candidate aircraft fuels

5 Comparison of statistics of the observed air temperature at South Pole Station to the FP specification for candidate aircraft fuels

6 Comparison of estimated statistics of air temperature at WAIS Divide camp (based on temperature data obtained from Byrd Station [Appendix A]) to the freeze temperature specification for candidate aircraft fuels.

7 Comparison of the estimated minimum fuel temperature at WAIS Divide camp to the freeze temperature specification for candidate aircraft fuels. This estimate is based on temperature data obtained from Byrd Station (Appendix A) and applying a 20-day running average to the data, assuming that is takes approximately 20 days for the stored fuel to equilibrate with the air temperature

8 Estimated temperature at 18,000 ft altitude at McMurdo, Antarctica................................26

9 Estimated temperature at 18,000 ft altitude at South Pole Station...................................27

10 Estimated temperature at $18,000 \mathrm{ft}$ altitude at WAIS Divide camp ..................................2

\section{Tables}

1 Yearly cost of USAP bulk fuel from the refinery based on the type of fuel (does not include transportation costs)

2 Physical properties of hydrocarbon molecules typical in the composition of kerosene. The freezing temperature reported in this table is associated with "constant" temperature fusion of a liquid to a solid for a pure substance and differs from the freeze-point specification for aviation fuels given elsewhere in this report.

3 Freeze-point (FP) specification for some aviation fuels that may be applicable for

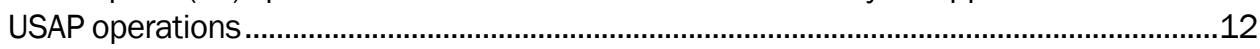

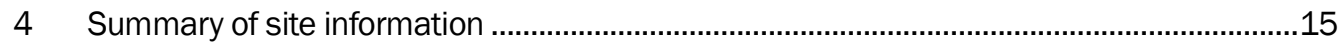

5 Estimated drop in air temperature at the indicated flight altitudes near three locations in Antarctica...

6 The current opening and closing dates at McMurdo, South Pole, and WAIS Divide compared to the approximate required start and end dates of air operations at the same sites if JP-8 were used. 


\section{Preface}

This study was conducted for the National Science Foundation (NSF), Office of Polar Programs (OPP), under EP-ANT-14-23, "Antarctic Fuel Options."

The work was performed by the Terrestrial and Cryospheric Sciences Branch (CEERD-RRG) and the Force Projection and Sustainment Branch (CEERD-RRH) of the Research and Engineering Division (CEERD-RR), U.S. Army Engineer Research and Development Center, Cold Regions Research and Engineering Laboratory (ERDC-CRREL). At the time of publication, Ms. J anet Hardy was the program manager for EPOLAR Antarctica; Ms. Erin Bodie was Chief, CEERD-RRH; and CDR J . D. Horne, USN (Ret.) was Chief, CEERD-RR. The Deputy Director of ERDC-CRREL was Dr. Lance Hansen, and the Director was Dr. J oseph L. Corriveau.

We want to thank Mr. Alexander Morris, Antarctic Support Contractor (ASC), and Ms. J anet Hardy, CRREL, for their thoughtful technical reviews of this manuscript.

COL Bryan S. Green was Commander of ERDC, and Dr. David W. Pittman was the Director. 


\section{Acronyms and Abbreviations}

\begin{tabular}{|c|c|}
\hline ASC & Antarctic Support Contractor \\
\hline CFPP & Cold Filter Plugging Point \\
\hline $\mathrm{CP}$ & Cloud Point \\
\hline CRREL & Cold Regions Research and Engineering Laboratory \\
\hline DESC & Defense Energy Support Center \\
\hline EPOLAR & Engineering for Polar Operations, Logistics, and Research \\
\hline ERDC & U.S. Army Engineer Research and Development Center \\
\hline FP & Freeze Point \\
\hline GSOD & Global Summary of the Day \\
\hline $\mathrm{HC}$ & Hydrocarbon \\
\hline IPCS & International Programme on Chemical Safety \\
\hline KBA & Kenn Borek Air \\
\hline LTFT & Low-Temperature FlowTest \\
\hline MEDEVAC & Medical Evacuation \\
\hline MGO & Marine Gas Oil \\
\hline MSC & Military Sealift Command \\
\hline MSDS & Material Safety Data Sheet \\
\hline MSL & Mean Sea Level \\
\hline NCDC & National Climatic Data Center \\
\hline NSF & National Science Foundation \\
\hline NYANG & NY Air National Guard \\
\hline OPP & Office of Polar Programs \\
\hline
\end{tabular}




$\begin{array}{ll}\text { PP } & \text { Pour Point } \\ \text { SPoT } & \text { South Pole Operations Traverse } \\ \text { USAP } & \text { U.S. Antarctic Program } \\ \text { USNS } & \text { U.S. Naval Ship } \\ \text { WAIS } & \text { West Antarctic Ice Sheet } \\ \text { WINFLY } & \text { Winter Fly-In (of equipment, etc.) }\end{array}$




\section{Unit Conversion Factors}

\begin{tabular}{|l|l|l|}
\hline Multiply & By & To Obtain \\
\hline degrees Fahrenheit & $(\mathrm{F}-32) / 1.8$ & degrees Celsius \\
\hline feet & 0.3048 & meters \\
\hline gallons (U.S. liquid) & $3.785412 \mathrm{E}-03$ & cubic meters \\
\hline miles (U.S. statute) & $1,609.347$ & meters \\
\hline
\end{tabular}




\section{Executive Summary}

The National Science Foundation (NSF), single point manager for the U.S. Antarctic Program (USAP), places an annual bulk fuel purchase in September. This fuel is delivered in late J anuary each year and is intended to supply USAP's two largest stations (McMurdo and Amundsen-Scott South Pole) and remote camps for an entire year. Bulk fuel delivery is challenging due to extreme environmental conditions and the logistical support required at such a remote destination. Maximizing program efficiency while minimize costs going into the future, it is essential to determine the correct fuel required for Antarctic conditions.

Currently, USAP has standardized on using a unique aviation fuel (AN8) for all air operations and for the majority of its ground-based activities (heating, power generation, heavy equipment fleet, etc.). The freeze-point (FP) specification for AN8 is $-58^{\circ} \mathrm{C}$, which is not lower than commonly reached austral winter ambient temperatures at several of USAP's continental stations and camps. However, all USAP stations have systems in place that prevent freezing of stored AN8.

The U.S. Army Cold Regions Research and Engineering Laboratory (CRREL) conducted an analysis of the air temperature history at McMurdo, South Pole, and the WAIS (West Antarctic Ice Sheet) Divide camp to determine the conditions under which USAP could use fuels other than AN8 that potentially are less costly and more readily available on the commercial market.

J P-8 and J et A-1 (both commonly available aviation fuel types, unlike AN8) have an FP specification of $-47^{\circ} \mathrm{C}$. Although these fuels freeze at a temperature $11^{\circ} \mathrm{C}$ warmer than $\mathrm{AN} 8$, their FP is below the minimum average daily air temperature at McMurdo $\left(-40^{\circ} \mathrm{C}\right)$ and is also below the storage temperature of fuel at South Pole $\left(-45^{\circ} \mathrm{C}\right)$. Furthermore, the estimated ambient temperature at the most fuel-demanding remote field camp (WAIS Divide) is above the FP of J P-8 during that camp's operational season (the austral summer). Based on these findings, it may be possible to use the more commonly available J P-8 for all ground-based applications where AN8 is currently used.

At all of these locations, the temperature at altitude for flight operations is below the FP of J P-8 for extended periods of the operational season. 
Therefore, it is possible that use of J P-8 for flight operations may shorten the regular operational flight season at some inland locations on the Antarctic continent. Yet, though the winter temperatures at flight level are below the FP of J P-8, C-17s routinely carry out winter missions to McMurdo fueled with J et A-1 (which has the same FP as J P-8) received from Christchurch, NZ. However, these winter missions have limited ground time in Antarctica, and often the aircraft engines are not shut down. Still, the fuel in the C-17 tanks, during flight and when on the ground, suffers exposure to ambient temperatures persistently below $-47^{\circ} \mathrm{C}$ for most, if not all, of the approximately 12-hour round-trip mission. This suggests that use of JP-8 may not have a significant impact on reducing scheduled flights.

Calculation of NSF's fuel cost per gallon is not straightforward as a result of both the complex logistics (e.g., the need for a heavy icebreaker to allow a tanker to reach McMurdo where bulk storage infrastructure exists) and the process used by the NSF's fuel purchasing agent (Defense Logistics Agency). This report also summarizes how NSF makes fuel purchases and lays out several scenarios that consider how using a combination of J P-8 and AN8 may meet the needs of air- and ground-based operations in USAP. Additional study is required to determine relative cost and feasibility of each of these approaches. We recommend further studies to verify that any fuel used in the USAP can sustain a freeze- thaw cycle (such as would be experienced in the austral winter at a remote, unoccupied location like WAIS Divide) and continue to perform adequately under typical operational conditions after thaw. 


\section{Introduction}

\subsection{Background}

The primary fuel type used in the U.S. Antarctic Program (USAP), managed by National Science Foundation (NSF), is a highly refined aviation fuel (AN8) and is intended for use in as many applications as possible. In addition to being used for aircraft operations (fixed and rotary wing), AN8 is used for ground-based applications (e.g., electric generators, facilities heating boilers, heavy equipment, etc.) that would normally use diesel and fuel oil in warmer climates. This "single-fuel" approach reduces the need for multiple fuel types stored in separate tanks and the need to keep track of which fuel type needs to be used for each application. USAP is not able to completely implement a single-fuel concept since some vehicles require "mogas," or gasoline, to operate; and J P-5 must be stored at McMurdo for refueling of the most commonly used icebreaker (U.S. Coast Guard) and USAP research vessels. Yet, the overarching concept is to minimize as much as possible the need for storing large quantities of differing fuels.

Currently, USAP has standardized on the low-temperature AN8 aviation fuel to fulfill as much as possible a single-fuel concept. This fuel has a FP specification of $-58^{\circ} \mathrm{C}$ and has been specifically formulated for Antarctic use. Because AN8 is not a standard commercial product and must be specially refined, at times in the past it has cost considerably more than other standard aviation fuels, such as J et A-1 (or J P-8) and J et A. For example, during the period of 2005- 2012, the cost of AN8 ranged from 6\% to 76\% higher than J et A (comparing the AN8 purchase cost to the internationally indexed pricing of J et A) and was on average $26 \%$ higher than J et A. More recently, AN8 has cost the same or a few cents less than J P-5 and J P-8 (the cost for these two fuels is about the same). Still, there is concern that in the future a specialized fuel like AN8 will become more expensive than J P-5 (and J P-8). Furthermore, the drastic increase and volatility in the cost of aviation fuel in general, as illustrated in Figure 1, is a cause for concern for budgeting and controlling costs within USAP. Any savings in fuel cost, however small, can reap a big benefit for the program, considering the amount of fuel delivered to McMurdo annually (approximately six million gallons). 
Figure 1. Platts' Jet A fuel prices per gallons from 1990 to 2013. Platts' pricing is a real time market process for determining the cost of fossil fuels. This process takes into account supply, demand, and current events. Since 1909, Platts has been reporting these real time prices and benchmark price assessments (Platts 2017).

\section{Jet Fuel Prices}

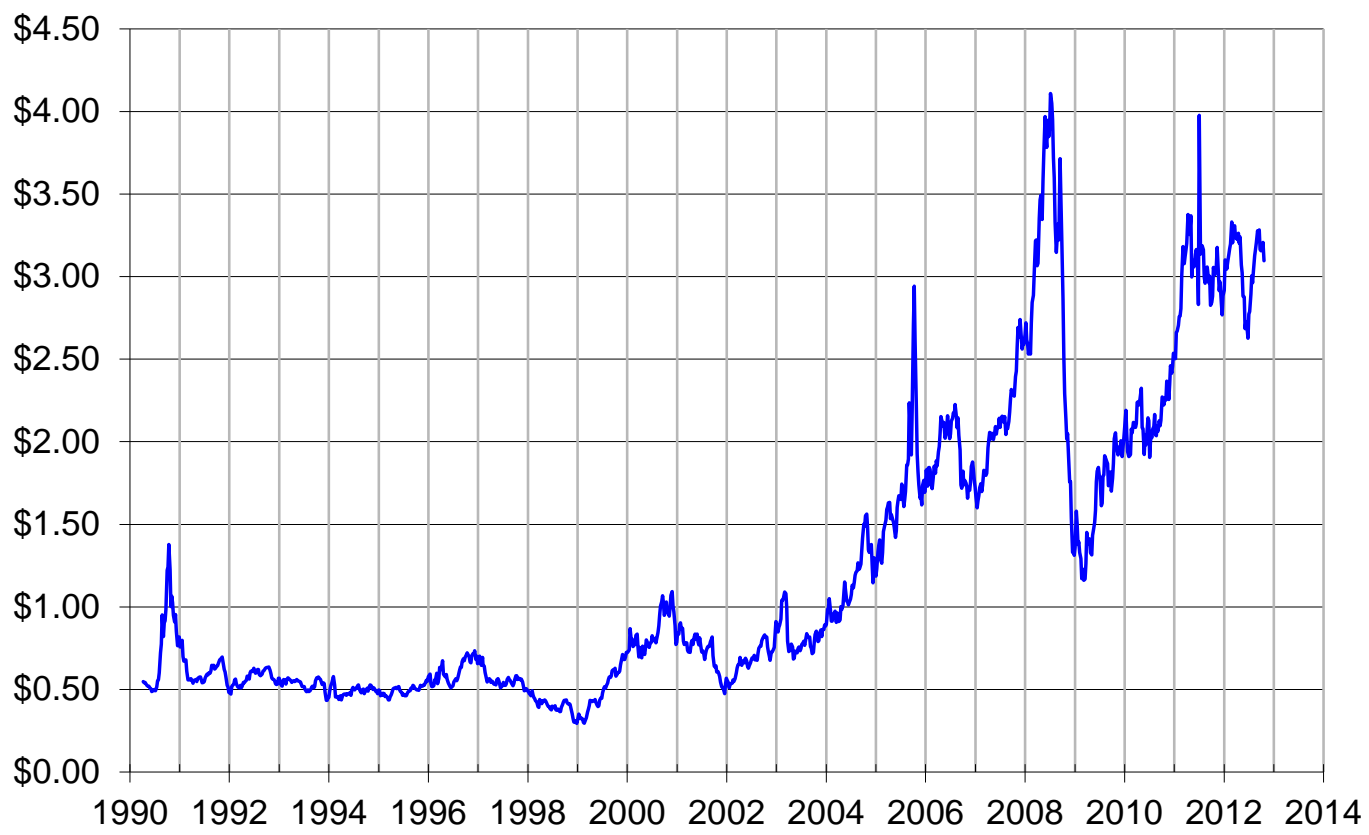

\subsection{Objective}

In this study, we evaluate the temperature regime at several key locations used by USAP to determine the need for continued use of AN8 or if the use of an alternate "warmer" temperature, and potentially less expensive, fuel would provide adequate low-temperature performance and could replace AN8 in the future.

\subsection{Approach}

USAP has three permanent stations, McMurdo, Amundsen-Scott South Pole, and Palmer, and supports numerous field camps on the Antarctic continent. In this study, we consider the temperature regime at two of the three stations. We do not include Palmer Station in this analysis because the station does not support aviation activities and, owing to its lower latitude compared to other USAP sites of activity, higher air temperatures at Palmer allow use of fuels with warmer freeze points (such as diesel). 
We also consider the largest recurring field camp (WAIS [West Antarctic Ice Sheet] Divide), owing to the harsh temperature environment experienced there and its being a site of long-term, concentrated aviation activity annually during the austral summer. It is one of the coldest camps supported by USAP, and we use it to represent the extreme case for camps in general as well as fuel cache locations (e.g., used by contract DHC-6 Twin Otter aircraft that support the USAP).

We first discuss how NSF purchases USAP's bulk fuel needs and how total price is calculated (section 2). A detailed analysis follows of low-temperature performance specifications of aviation fuels and compatibility of aviation fuels with the LC-130 Hercules (ski-wheel) aircraft used in USAP operations (section 3). In section 4, we review the temperature records at the three key sites mentioned above to determine fuel compatibility with ground operations. Section 5 provides an assessment of the compatibility of various aviation fuels for use in air operations in the USAP. We then outline several scenarios for fuel usage in the USAP (section 6). These scenarios are only identified in this effort. Full evaluation of these cases is planned as a future effort. In section 7 , we provide conclusions and recommendations derived from this effort. 


\section{Fuel Purchasing}

The purchasing of large quantities of fuel for delivery to Antarctica (approximately six million gallons annually) is not a trivial task. The NSF begins the annual bulk USAP fuel purchasing process by contacting the $\mathrm{De}$ fense Energy Support Center (DESC, a department within the Defense Logistics Agency) with an estimate of the quantity of fuel they intend to purchase. NSF also provides DESC with the date by which the fuel must be delivered to McMurdo Station (commonly a date in the last week of J anuary or the first two weeks of February).

The U.S. Navy Military Sealift Command (MSC) provides NSF with bulk fuel transport services. Thus, as soon as NSF confirms that DESC will solicited bids for its bulk fuel needs, NSF contacts MSC, indicating the amount of fuel intended to be purchased and the date by which it needs to arrive in McMurdo. MSC then begins work to source an appropriately sized ship with ice-strengthened hull to be available during a time block dictated by the location of the winning refinery, its distance from McMurdo, and NSF's stated delivery date. Once MSC has a tanker under contract for the McMurdo delivery mission, it advises NSF of the "day rate" (the daily charge for the tanker from the day it arrives at the refinery to upload NSF's fuel to the day it arrives at a destination where it will perform work for a different customer). Over the past decade, day rates have ranged between about $\$ 25,000$ and $\$ 70,000$. Typically, the duration of NSF's responsibility for paying for the tanker is about 90 days, which includes the approximately 5 days it spends docked in McMurdo off-loading fuel and reballasting with seawater.

Because MSC is accustomed to working with DESC for satisfying government agencies' bulk fuel needs, communications between the two agencies is ongoing through the fuel contract award process. Therefore, the actual date the fuel must be available at the refinery for pick-up by MSC to be delivered on time to McMurdo is coordinated without the need for NSF involvement.

Once NSF contacts DESC, DESC issues a request for bids in September from refiners, stating how much fuel will be purchased and the approximate date for pick-up by MSC (typically about 15 December). In an effort to achieve pricing fairness to both the government and the fuel vendor, the 
cost proposed by bidders is prescribed by DESC to be linked to an international independent energy index (Platts 2017). Since 1909, Platts has provided benchmark prices for commodities and energy markets worldwide based on supply, demand, and current environmental and political events. In short, in the solicitation, DESC requests that the bidders quote a cost per gallon for NSF's fuel as if the fuel had been provided to the government on a date in the recent past (often a day in the previous J uly) and specifying which Platts' indexing region to reference. Bidders take into account a number of factors when proposing cost to DESC, including their estimates of the difficulty of obtaining feedstock, the cost for NSF's fuel at the time it will need to be refined to meet the required delivery date, and profit. The difference between the vendor's quoted cost of fuel and the Platts' index value of jet fuel on the date DESC prescribed for reference can be viewed as the vendor's markup. DESC evaluates the bidders based first on their ability to meet the fuel specifications given in the solicitation (e.g., ultra-low sulfur content and extreme-low-temperature freeze point) and then on lowest cost. Except for competition, there is no other restraint on the magnitude of a bidder's markup.

The markup value is really the only important number in the solicitation process. This is because, in the solicitation, DESC indicates that the winning bidder will be paid a price per gallon equal to the 10-day average of Platts' value of jet fuel leading up to and including the day it is uploaded onto the MSC tanker, plus the markup. This protects the vendor from an uncontrollable uptick in feedstock costs between the time of proposal and when the fuel is refined. Likewise, it protects the government from being gouged should feedstock cost drop during the bid-to-pick-up interval.

Using this scheme, the total fuel product cost to NSF is (a) the 10-day average Platts' fuel price for the days leading up to and including the date of commencement of tanker upload, plus (b) the winning bidder's markup, plus (c) a per-gallon "administrative fee" levied by DESC (usually a few tenths of a cent). Table 1 lists the types and quantities of NSF's bulk fuel for Antarctica in recent years and their cost per year. 
Table 1. Yearly cost of USAP bulk fuel from the refinery based on the type of fuel (does not include transportation costs).

\begin{tabular}{|c|c|c|c|c|c|}
\hline Year & Fuel Type & $\begin{array}{l}\text { Quantity } \\
\text { Purchased } \\
\text { (gal.) }\end{array}$ & $\begin{array}{l}\text { Unit Cost } \\
\text { (\$/gal.) }\end{array}$ & \multicolumn{2}{|c|}{$\begin{array}{l}\text { Total Product Cost } \\
(\$)\end{array}$} \\
\hline \multirow[t]{3}{*}{2005} & AN8 & $3,532,890$ & 1.43 & $5,052,033$ & \multirow[t]{3}{*}{$8,823,043$} \\
\hline & JP-5 & $2,582,884$ & 1.46 & $3,771,011$ & \\
\hline & MOGAS & 0 & 0.00 & 0 & \\
\hline \multirow[t]{3}{*}{2006} & AN8 & $3,861,143$ & 1.83 & $7,065,892$ & \multirow[t]{3}{*}{$11,942,242$} \\
\hline & $J P-5$ & $2,492,456$ & 1.91 & $4,760,591$ & \\
\hline & MOGAS & 74,205 & 1.56 & 115,760 & \\
\hline \multirow[t]{3}{*}{2007} & AN8 & $3,641,167$ & 2.08 & $7,573,627$ & \multirow[t]{3}{*}{$14,354,151$} \\
\hline & JP-5 & $3,027,086$ & 2.15 & $6,508,235$ & \\
\hline & MOGAS & 152,971 & 1.78 & 272,288 & \\
\hline \multirow[t]{3}{*}{2008} & AN8 & $3,871,300$ & 2.85 & $11,033,205$ & \multirow[t]{3}{*}{$17,947,041$} \\
\hline & $J P-5$ & $2,233,800$ & 2.97 & $6,634,386$ & \\
\hline & MOGAS & 115,000 & 2.43 & 279,450 & \\
\hline \multirow[t]{3}{*}{2009} & AN8 & $4,932,325$ & 1.95 & $9,618,034$ & \multirow[t]{3}{*}{$10,738,534$} \\
\hline & JP-5 & 485,385 & 2.02 & 980,478 & \\
\hline & MOGAS & 119,677 & 1.17 & 140,022 & \\
\hline \multirow[t]{3}{*}{2010} & AN8 & $4,626,297$ & 2.456214 & $11,363,175$ & \multirow[t]{3}{*}{$12,526,117$} \\
\hline & $J P-5$ & 349,802 & 2.499024 & 874,164 & \\
\hline & MOGAS & 113,754 & 2.538619 & 288,778 & \\
\hline \multirow[t]{3}{*}{2011} & AN8 & $4,199,225$ & 3.001170 & $12,602,588$ & \multirow[t]{3}{*}{$16,003,031$} \\
\hline & $J P-5$ & $1,002,244$ & 2.988194 & $2,994,900$ & \\
\hline & MOGAS & 149,777 & 2.707651 & 405,544 & \\
\hline \multirow[t]{3}{*}{2012} & AN8 & $5,304,697$ & 3.560928 & $18,889,644$ & \multirow[t]{3}{*}{$22,738,233$} \\
\hline & JPP-5 & 994,990 & 3.560928 & $3,543,088$ & \\
\hline & MOGAS & 100,140 & 3.050738 & 305,501 & \\
\hline \multirow[t]{3}{*}{2013} & AN8 & $5,503,156$ & 3.528660 & $19,418,766$ & \multirow[t]{3}{*}{$20,971,007$} \\
\hline & $J P-5$ & 350,475 & 3.537967 & $1,239,969$ & \\
\hline & MOGAS & 99,990 & 3.123025 & 312,271 & \\
\hline \multirow[t]{3}{*}{2014} & AN8 & $2,100,649$ & 3.658400 & $7,685,014$ & \multirow[t]{3}{*}{$12,784,867$} \\
\hline & $J P-5$ & $1,301,924$ & 3.663500 & $4,769,599$ & \\
\hline & MOGAS & 113,009 & 2.922372 & 330,254 & \\
\hline \multirow[t]{3}{*}{2015} & AN8 & $4,500,000$ & 2.408437 & $10,837,967$ & \multirow[t]{3}{*}{$12,047,168$} \\
\hline & $J P-5$ & 500,000 & 2.418403 & $1,209,202$ & \\
\hline & MOGAS & 0 & 0 & -- & \\
\hline
\end{tabular}

Table 1 gives insight into how variable the cost of manufacturing fuel is from year to year. The costs in the table do not take into account the cost 
of transporting the fuel, icebreaker services, and McMurdo Fuels Department equipment and labor costs. (Icebreaking typically costs between $\$ 2.5 \mathrm{M}$ and $\$ 10 \mathrm{M}$ per year-depending on the availability of a domestic icebreaker vs. a foreign contract ship—-plus about \$1M in ship fuel cost.)

Having described cost for delivery of fuel to McMurdo Station, it is important to note that, when evaluating fuel bids, DESC also does not take into account refinery location. Thus, while the difference in cost between the winning bidder and other bids may be a few cents per gallon (overall approximately $\$ 120,000$ for a $\$ 0.02$ difference), every extra day of tanker travel to reach a refinery farther from McMurdo can rack up major costs to NSF (in some years, 4 days extra of tanker travel time have an added cost of $\$ 280,000)$.

The ability of NSF to respond to market fluctuations and other factors in the timing of its bulk fuel purchase is very limited. A typical business strategy would be to purchase fuel only at times when the price is attractive or when reserves are low and demand that a purchase be made. Likewise, the quantity purchased at any one time would be based on market cost, reserves on hand, budget timing, and other strategic factors. However, delivery timing to McMurdo Station is very challenging due to the constraints of the entire Ross Sea being ice covered for over 9 months of each year and sea ice forming in and persistent throughout the austral summer in southern McMurdo Sound adjacent to McMurdo Station. The current timing of tanker (and cargo ship) visits to McMurdo are based on a tight window when natural forces have (a) weakened McMurdo local sea ice and eroded the ice edge southerly as close to McMurdo as possible and (b) created as much as possible a floe-ice-free corridor through the northern Ross Sea. Because this window is so tight and only occurs once a year, there is little ability for NSF to change the delivery time without requiring longer and more difficult icebreaking services and hence additional costs.

NSF could perhaps still gain flexibility in its fuel purchase timing if it established an off-continent (non-Antarctic) storage facility. This could be a dedicated reserve or perhaps a rent-as-needed facility. This approach would require additional tanker movements and facilities costs, which may or may not outweigh speculative fuel-purchase timing. To help determine if this might be feasible, we compared the cost of a USAP-typical 9-year supply of jet fuel by month of purchase (Figure 2). We used Platts' average 
monthly jet-fuel cost values based on historical purchase request by NSF for the years 2005-2013 to make this calculation.

Figure 2. Estimated AN8 fuel cost comparison for all months over a 9-year period based on the Platts' pricing for aviation fuel from 2005 to 2013.

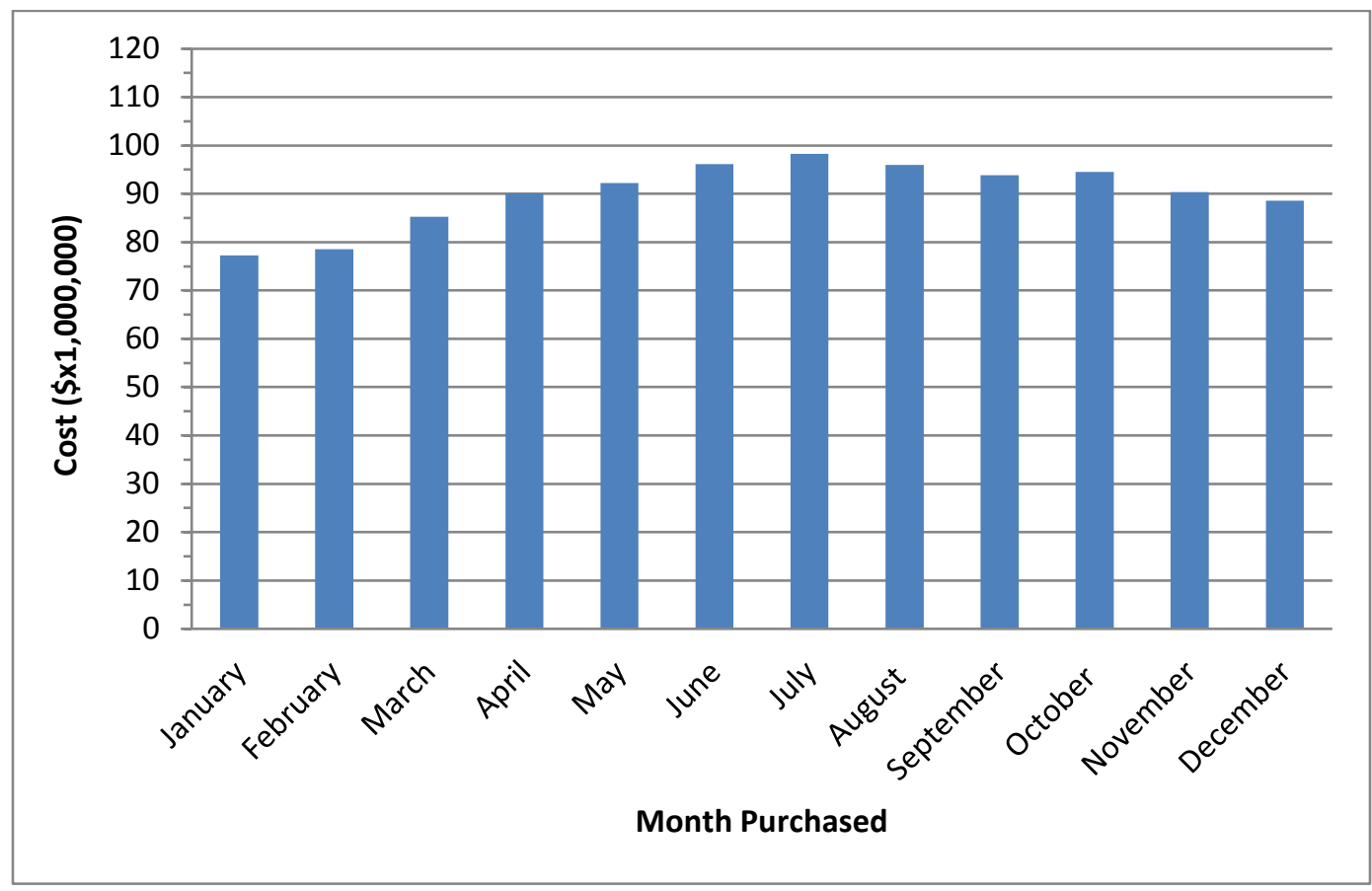

Figure 2 shows J uly is historically the most expensive month to purchase USAP-type fuel. If USAP's jet fuel costs were established in J uly every year, it would cost \$10 million more over a 9-year period compared to the price of the same amount of fuel cost-set in December (as is done now). J anuary is the cheapest month to purchase fuel, and the trend does show that the early months of each year show a steady increase in cost until J uly and then typically decrease through December. If USAP's jet fuel was cost-set in J anuary, Figure 2 suggests that fuel costs would be $\$ 11$ million less over the 9-year period considered in this comparison.

Removing the logistical constraint of purchasing fuel with a pick-up date of mid-December and pushing this date to the second week of J anuary may realize a significant cost savings as illustrated in Figure 3; this comparison is made using six million gallons of AN8 as the fuel purchased. By comparing the Platts' index cost for jet fuel for 12 December and 15J anuary over the period 2002 to 2010, there is only one year (2008) when the NSF would not have saved significantly by delaying the fuel purchase by about a month. (Note that the 2008 comparison of purchase dates bridged the massive and rapid drop in fuel prices shown in Figure 1 and 
that this kind of fluctuation in fuel prices is very uncommon.) This analysis suggests that NSF should pursue vetting options for changing fuel purchase/ uplift by a mere four weeks as it may achieve a significant cost savings.

Figure 3. AN8 fuel cost comparison for December and January when purchasing six million gallons.

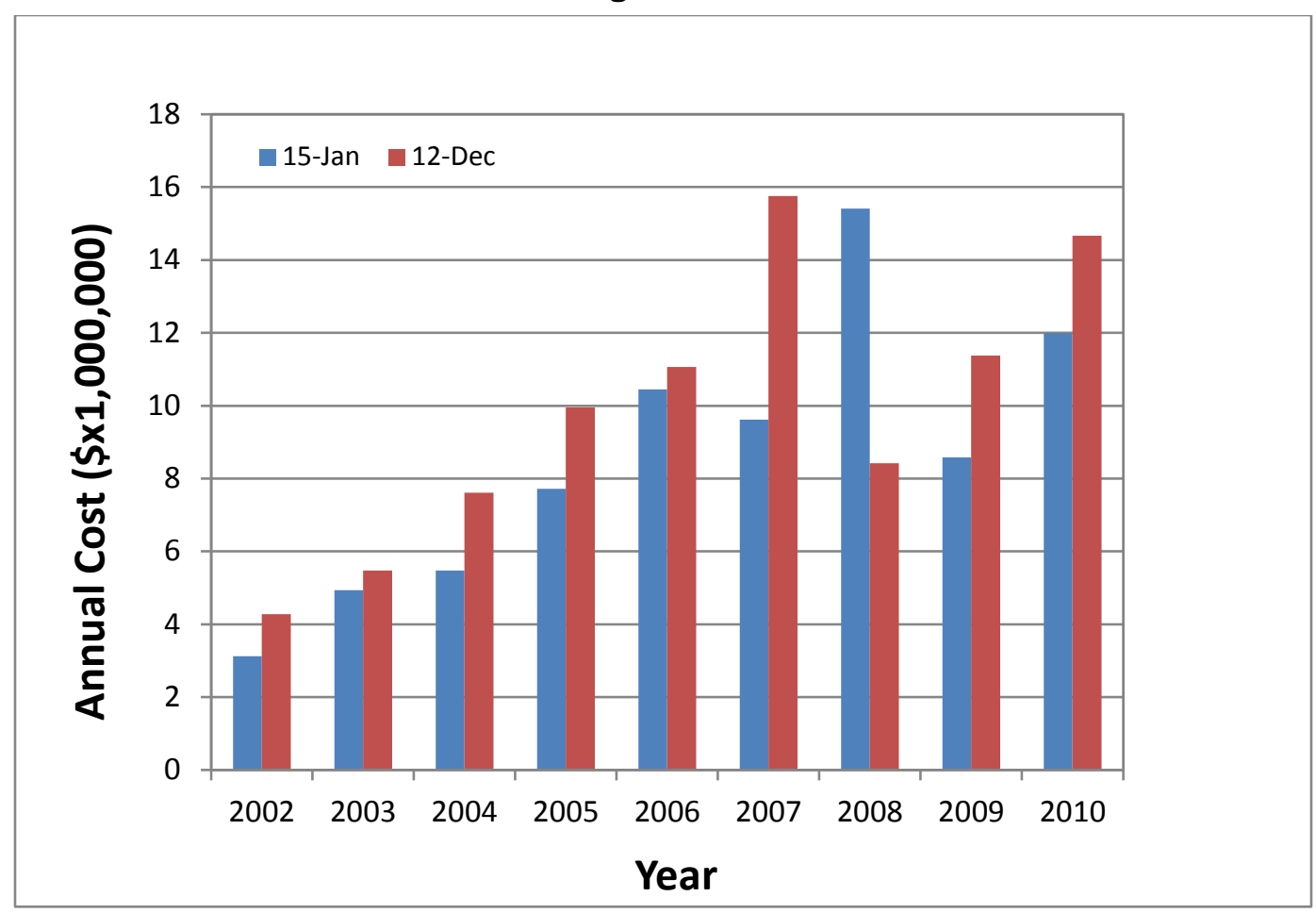




\section{Fuel Specifications and Aircraft Compatibility}

Considering the multiuse application of the fuel within USAP, it is appropriate to discuss the various low-temperature specifications associated with the intended use of the fuel. First, aviation fuel is principally composed of kerosene. Kerosene oil is obtained from the fractional distillation of petroleum between the temperatures of $150^{\circ} \mathrm{C}$ to $275^{\circ} \mathrm{C}$, yielding a mixture of hydrocarbon (HC) molecules that contain 6 to 16 carbon atoms. Kerosene is a combination of straight chain (paraffin [saturated HC chains] and olephin [unsaturated HC chains]) and ringed (aromatic: benzenes and naphthalenes) HCs. The range in freezing temperature of HCs in this molecular size range is $80^{\circ} \mathrm{C}$ to $-151^{\circ} \mathrm{C}$ as shown in Table 2 . However, the International Programme on Chemical Safety (IPCS 1998) reported the "melting point" of standard kerosene oil (also known as no. 1 fuel oil) as $-20^{\circ} \mathrm{C}$ (IPCS 1998). We presume that standard kerosene oil is further refined to obtain acceptable low-temperature performance for aviation use. For example, for AN8, further refinement (e.g., cracking or more refined distillation) is needed to achieve the target low-temperature performance required for that fuel. To better understand the considerations when selecting fuels for use in the wider range of Antarctic applications, we discuss the low-temperature specification for aviation fuels in the following section (section 4).

\footnotetext{
* IPPCS does not define what it means by "melting point" in this context. As standard kerosene oil is a mixture, it is more appropriate to report a range for the melting point. We do not further explore the definition of melting point within this report but provide the reported melting point as a point of reference for comparison to the information in Table 2. Later in this report, we provide precise definitions of specific fuel specifications applicable to aviation and Antarctic applications.
} 
Table 2. Physical properties of hydrocarbon molecules typical in the composition of kerosene. The freezing temperature reported in this table is associated with "constant" temperature fusion of a liquid to a solid for a pure substance and differs from the freeze-point specification for aviation fuels given elsewhere in this report. The compounds that are listed in red and blue have freezing temperatures lower than that of the freeze-point specification for JP-8 while those that are blue have freezing temperatures lower than the freeze-point specification for AN8.

\begin{tabular}{|c|c|c|}
\hline Compound & Freezing Temperature $\left({ }^{\circ} \mathrm{C}\right)$ & Density $\left(\mathrm{kg} / \mathrm{m}^{3}\right)$ \\
\hline \multicolumn{3}{|c|}{ Paraffins $(\mathrm{CnH}[2 \mathrm{2n}+2])$} \\
\hline Hexane (C6H14) & -96 to -94 & 655 \\
\hline Heptane (C7H16) & -91 & 684 \\
\hline Octane (C8H18) & -57 & 703 \\
\hline Nonane $(\mathrm{C9H} 2 \mathrm{O})$ & -51 & 718 \\
\hline Decane $(\mathrm{C} 10 \mathrm{H} 22)$ & -30.5 to -29.2 & 730 \\
\hline Undecane $(\mathrm{C} 11 \mathrm{H} 24)$ & -26.6 to -25 & 740 \\
\hline Dodecane $(\mathrm{C} 12 \mathrm{H} 26)$ & -10 to -9.3 & 749 \\
\hline Tridecane (C13H28) & -5 & 756 \\
\hline \multicolumn{3}{|c|}{ Olefins $(\mathrm{CnH} 2 \mathrm{n})$} \\
\hline Hexene (C6H12) & -139.8 & 673 \\
\hline Heptene (C7H14) & -119 & 697 \\
\hline Octene (C8H16) & -151.1 & 715 \\
\hline Nonene (C9H18) & -81 & 730 \\
\hline Decene $(\mathrm{C} 10 \mathrm{H} 20)$ & -66.3 & 740 \\
\hline Undecene (C11H22) & -49 & 750 \\
\hline Dodecene (C12H24) & -35.2 & 758 \\
\hline Tridecene $(\mathrm{C} 13 \mathrm{H} 26)$ & -23 & 766 \\
\hline \multicolumn{3}{|c|}{ Aromatics (single or double carbon rings) } \\
\hline Benzene (C6H6) & 5.5 & 877 \\
\hline Cyclohexane (C6H12) & 6.5 & 778 \\
\hline Toluene (C7H8) & -95 & 867 \\
\hline m-xylene (C8H10) & -47.9 & 870 \\
\hline o-xylene (C8H10) & -24 & 870 \\
\hline $\mathrm{p}$-xylene (C8H10) & 13.3 & 870 \\
\hline 1,2,4-trimeythlbenzene $(\mathrm{C} 9 \mathrm{H} 12)$ & -46.8 & 976 \\
\hline 1,3,5-trimeythlbenzene (C9H12) & -45 & 864 \\
\hline 1,2,3-trimeythlbenzene $(\mathrm{C} 9 \mathrm{H} 12)$ & -25 & 890 \\
\hline Naphthalene (C1OH8) & 80.3 & 1140 \\
\hline
\end{tabular}




\subsection{Low-temperature performance of fuels}

For aviation fuels, a freeze-point (FP) specification is given as the temperature at which all visible crystals have melted after heating previously frozen fuel, which dictates that fuel above its measured FP consists of a single liquid phase (Zabarnick and Ervin 2010). The FP is measured using standard test procedures found in ASTM (2012). FP is a definition applicable for aviation fuels only and will be the only definition of FP we use. (Note that FP is not to be confused with the freezing temperature of a pure substance [e.g., as reported in Table 2] or the freeze temperature reported for fuels used for ground-based applications [e.g., diesel fuel], which from the literature appears to be closer to the pour point discussed below.)

Table 3 lists the FP specifications for several candidate fuels that may be applicable for Antarctic use. We found in several sources (Zabarnick and Ervin 2010; Zabarnick et al. 2013; Hadaller and J ohnson 2006; and fuel certification reports) that the measured FP of many aviation fuels is lower than the specification.

Table 3. Freeze-point (FP) specification for some aviation fuels that may be applicable for USAP operations.

\begin{tabular}{|l|c|}
\hline \multicolumn{1}{|c|}{ Fuel } & Freeze-Point Specification $\left({ }^{\circ} \mathrm{C}\right)$ \\
\hline Jet A & -40 \\
\hline JP-7 & -43.3 \\
\hline JP-5 & -46 \\
\hline JP-8, Jet A-1 & -47 \\
\hline AN8, JP-4 & -58 \\
\hline
\end{tabular}

There are two low-temperature specifications associated with fuels (mainly diesel) used for ground-based applications: the low-temperature flow test (LTFT) point, a North American standard (ASTM 2010), and the cold filter plugging point (CFPP), a European Standard. Both standards measure the temperature at which a specified volume of fuel can be pumped through a filter (filter type specified by the respective standard) within a specified timeframe. It is generally accepted that the LTFT provides a more representative temperature than the CFPP for the operational limits of the fuel, specifically the point at which a filter will become plugged (no longer allowing enough fuel through to operate the equipment) by solid crystals that have formed in the fuel. 
In an attempt to resolve some of the confusion on low-temperature fuel terminology, we provide definitions below of the more common terminology in order of warmest to coldest (or lowest viscosity to highest viscosity). Most of these terms are not specifications but are commonly used when discussing low-temperature performance of fuels.

1. Freeze point (FP): As defined at the beginning of subsection 3.1

2. Remix temperature: Term used primarily for diesel fuels and is the point at which all waxes and crystals in the fuel have melted when the fuel is warmed back up after crystal formation has occurred (This appears essentially to be the same as the FP as defined for aviation fuels. Remix temperature is used mainly within the European fuel community.)

3. Cloud point (CP): The point where enough crystallization has occurred to make the fuel visually cloudy (usually associated with low-temperature performance for diesel fuel, not aviation fuels)

4. Cold filter plugging point (CFPP) or low-temperature flow test (LTFT): When enough crystallization takes place within the fuel to plug a fuel filter of specified pore size (CFPP) or the viscosity and crystallites is sufficient to prevent flow through a $17 \mu \mathrm{m}$ mesh (LTFT) (Both are usually associated with low-temperature performance for diesel fuel, not aviation fuels.)

5. Pour point (PP): The point where the fuel no longer flows (usually associated with low-temperature performance for diesel fuel, not aviation fuels)

Gel point is a commonly used, however often misused, term when working with diesel fuel. Some references (mostly academic) treat this more or less synonymously with PP (or gelation temperature, the point where the viscosity of the fuel rises sharply). Forums that deal with practical applications of fuels report gel-point temperatures more in the range of and falling between the CP and LTFT/ CFPP. Because of this confusion on the true meaning of gel point and the fact that gel point is not a defined fuel specification, we will avoid using this term in this study but will rather use more definitive terms like FP, CP, and PP to describe the fluid state of the fuel.

Zabarnick and Ervin (2010) observe that the FP of aviation fuels is $2^{\circ} \mathrm{C}$ $6^{\circ} \mathrm{C}$ above the measured fuel CP; and Zabarnick et al. (2013) found that, on average, the measured $\mathrm{FP}$ is $3.34^{\circ} \mathrm{C}$ higher than the measured $\mathrm{CP}$ for that fuel and concludes that the FP is a very conservative specification as it requires that no crystallites are present in the fuel during operation. In contrast, the LTFT measurement indicates the temperature at which the equipment operation may cease due to plugging of the fuel filter. The 
LTFT is an acceptable standard for some ground-based applications where equipment failure may not create a life-threatening situation. Considering, however, that power and heat generation are critical support systems for the survival of staff stationed at Antarctic sites during winter months (when the chance of rescue is limited), the FP specification may be a more appropriate, conservative standard for the ground-based applications in Antarctica.

We also note that Zabarnick et al. (2013) observed that, in general, the PP is $4^{\circ} \mathrm{C}-6.5^{\circ} \mathrm{Clower}$ than the $\mathrm{CP}$ for many aviation fuels. Therefore, the temperature difference between the FP and PP for many aviation fuels appears to be typically in the narrow range of only $6^{\circ} \mathrm{C}$ to $13^{\circ} \mathrm{C}$.

\subsection{Aircraft fuel compatibility}

Before proceeding, it is worth discussing the compatibility of the fuels identified in Table 3 with the aircraft used in the Antarctic, particularly the LC-130, which transports supplies and personnel to South Pole Station and to other camps across the continent. Communications with the 109th Air Wing, NY Air National Guard (NYANG) (Herdrick 2013a), confirm that the only fuel listed in Table 3 that is incompatible with the LC- 130 is JP-7, a fuel developed for super-sonic aircraft. Furthermore, for military applications, fuel compatibility is classified as "recommended," "alternate," and "emergency." The only recommended fuels for the LC-130 aircraft are AN8 and J P-8. All of the remaining fuels (excepting J P-7) are listed as alternate fuels. We also note that J P-4 has been phased out of use in the Air Force due to its high flammability.

Based on this information, the only fuels that Antarctic operations can readily adopt for dual use are AN8 and J P-8. Any other fuel listed in Table 3 would need further review to determine the reasons for being listed as an alternate fuel (e.g., engine wear, limitations on range, climb rate, altitude, etc.) and to determine if there are compelling reasons to consider adopting any of those fuels over the recommended fuels. 


\section{Fuel Compatibility for Ground-Based Applications}

We obtained from the National Climatic Data Center (NCDC) air temperature data for McMurdo and South Pole for comparison to the FP specifications of candidate aviation fuels. For WAIS Divide camp, there was limited data available for calculating the temperature statistics-data dates back to only 2009-so we determined that a reasonable surrogate for WAIS Divide is the Byrd Station, approximately 100 miles from WAIS (Appendix A). Therefore, we used the data from Byrd Station to estimate the long-term temperature statistics for WAIS Divide.

Using the data from these sources, we completed a cyclic analysis for each site. We computed statistics for all the years in the period of record to obtain the max, min, average, and percentile information for each day of the year.

Table 4 provides a summary of the data for each of the four sites. We note that, though the period of record for these sites dates back several decades, there are some large gaps in the data. In Table 4 , we provide the average number of years of observations available for each site for calculating the statistics for the cyclic analysis. This illustrates the extent to which there is missing data in these records.

Table 4. Summary of site information.

\begin{tabular}{|l|c|c|c|}
\hline \multicolumn{1}{|c|}{ Location } & Period of Record & $\begin{array}{c}\text { Average Number } \\
\text { of Years of } \\
\text { Observations }\end{array}$ & Altitude (ft) \\
\hline McMurdo & Jan 1973-Jan 2014 & $36^{\dagger}$ & 0 \\
\hline South Pole & Jan 1973-Jan 2014 & 6 & 10,000 \\
\hline WAIS Divide* & May 1990-Jan 2014 & 13 & 5900 \\
\hline
\end{tabular}

* For this location, we are using the statistics from the Byrd Station as discussed in Appendix A.

† This average is for observations during the operational season only (i.e., summer months) for McMurdo; for the other sites, the number of observations is on average about the same throughout the entire year.

In Figures 4- 6, we compare the minimum observed air temperatures at McMurdo, South Pole, and WAIS Divide camp to the FP specification for each of the candidate fuels considered in this study. We consider each location in turn. 
Figure 4 shows the temperature statistics for McMurdo Station compared to the FP specification for each fuel that USAP could potentially use. Although it has little bearing on this study, Figure 4 also shows the maximum and mean air temperatures observed over the period of record (as listed in Table 4). We note that both of these statistics are computed based on the observed average daily air temperature. Therefore, the maximum shown in these figures is not the maximum temperature observed over the period of record, rather the maximum average daily temperature. Likewise, the minimum observed values presented here are the minimum daily average air temperature. The solid green line at the bottom of the figure reflects the number of observations for each day of the year. This shows that during the summer season, there were many more years of observation than for the winter. Originally, the weather data was recorded only during the summer season. More recently, the McMurdo weather station has been operational year round. During the winter months, there are generally about 20 observations* used for computing the temperature statistics while during the summer there are about 36 observations on average.

Figure 4. Comparison of statistics of the observed air temperature at McMurdo, Antarctica, to the FP specification for candidate aircraft fuels.

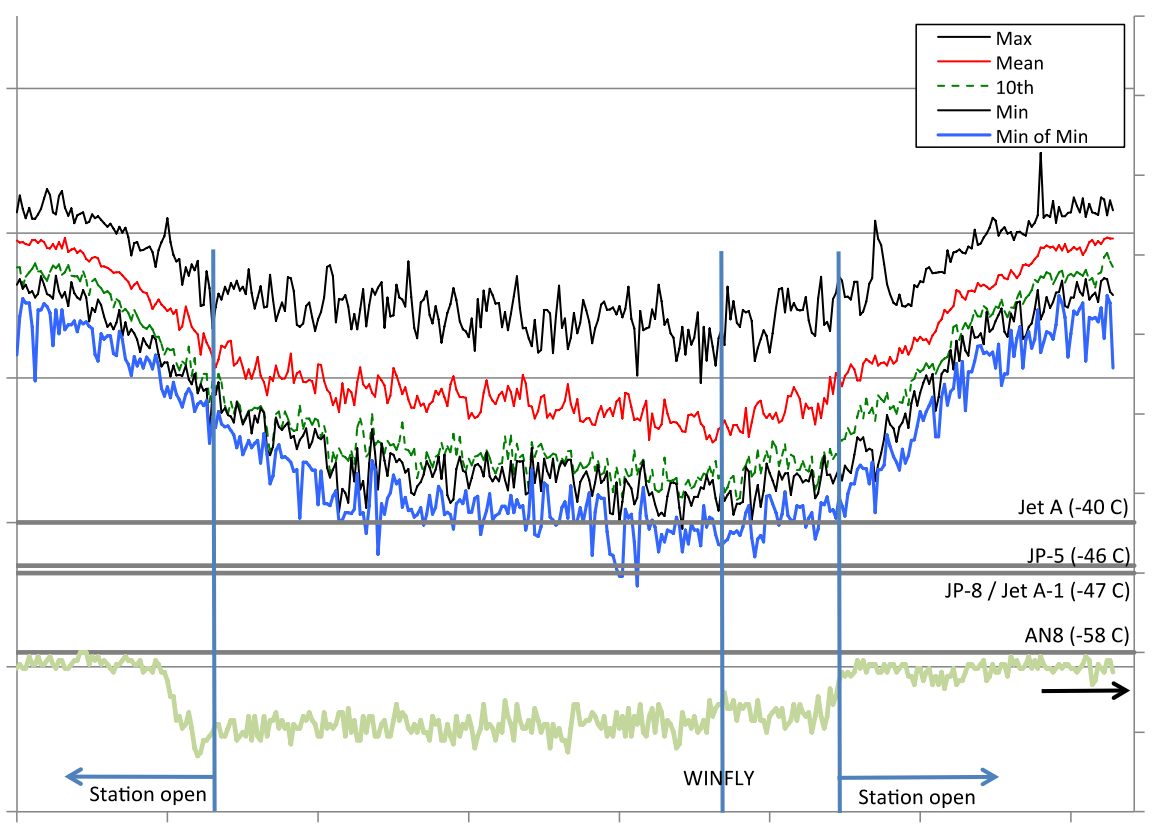

\footnotetext{
* By number of observations, we mean the number of years for which weather data was recorded for that day of the year.
} 
What is more germane to this study is the minimum air temperature statistics presented here: the 10th percentile, minimum average daily air temperature, and minimum of the minimum observed air temperature. We note that the 5th percentile temperature is indistinguishable from the minimum average daily air temperature, and therefore we did not include it in the figures. For fuel stored in a tank, the temperature of the fuel will reflect the average daily, or more likely weekly, temperature more closely than hourly fluctuations about the average value. For example, the amount of time for a tank containing 6 gal. of fuel to equilibrate with the air temperature (temperature variation in the tank is less than $30 \%$ different from the outside air temperature) is about 1 day (assuming a tank of this volume can be roughly approximated as a sphere). A bladder containing about $1000 \mathrm{gal}$. of fuel (this would look more like a $1.6 \mathrm{ft}[0.5 \mathrm{~m}]$ thick slab than a sphere) would take approximately 19 days to equilibrate with the air temperature. Because the 10th percentile and minimum temperatures plotted here are based on the average daily temperature, we consider them more representative of the fuel temperature fluctuations. For large tanks, a weekly average temperature would be more appropriate. Therefore, a comparison based on the average daily minimum is very conservative. Still, for reference, we also plot the absolute minimum temperature observed at this location over the period of record (often referred as the Min of Min).

Figure 4 shows that, even during the winter season in McMurdo, all of the fuels identified have freeze specifications that are generally below the lowest observed average daily air temperature. Even for J et A, there is only one day on record for McMurdo that has a minimum average daily air temperature below the $-40^{\circ} \mathrm{C}$ freeze specification. We note that the $\mathrm{C}-17 \mathrm{~s}$ and other aircraft that service McMurdo from Christchurch, NZ, are fueled in Christchurch with J et A-1* (even during mid-winter MEDEVAC [medical evacuation] flights), supporting the idea that use of fuels with a FP of as high as $-47^{\circ} \mathrm{C}$ may be acceptable for all applications at McMurdo. Figure 4 suggests that even J et A may be acceptable at McMurdo, at least for ground use.

Figure 5 compares the observed air temperatures at South Pole to the candidate fuels' FPs. Clearly, during the winter season, the air temperatures are well below the FP for all of the fuels considered. For some fuels (i.e.,

\footnotetext{
* See Christchurch International Airport Limited (2012).
} 
J et A), the maximum average daily air temperature is seldom above the FP. Yet, we note that the majority of the fuel is stored in tanks within the subsurface fuel arches at South Pole; and the temperature is maintained fairly constant at $-45^{\circ} \mathrm{C}$ (Knuth 2014). We note, however, that the temperature in the fuel arches may tend to get colder than that in the winter and warmer in the summer, though there is no temperature monitoring in the arches, so there is no documentation for how cold it actually gets (Morris 2015a) and whether the duration of the cold temperature in the arches is long enough to have a significant impact on the fuel temperature. Thus, we will tentatively say that for many ground-based applications (i.e., generators and boilers), all of these identified fuels except J et A may be acceptable. Vehicles that might operate outside (i.e., D-8 Caterpillar) during the winter months and any external storage tanks would require heated fuel tanks if a fuel other than AN8 were used at South Pole. The smallest of these external tanks is 50 gal., the next largest size is 175 gal., and the tanks continually increase in size (Knuth 2014). The size of these external tanks will be important when considering the heating requirements for external storage.

Knuth (2014) notes that the temperature of the fuel stored in these external tanks is approximately the same as the monthly average air temperature. We assume that a 30-day running average of the air temperature should provide a reasonable estimate of the fuel temperature in external tanks at South Pole. For comparison, Figure 5 shows a plot of the 30-day running average of the air temperature. We will discuss restrictions related to flight operations based on this data in the section 4 .

As a cautionary tale, we would like to clarify a point regarding some fuel problems experienced in the past at Palmer Station. In 2004, Marine Gas Oil (MGO), which lists only a gel point of $0^{\circ} \mathrm{C}$, was used and stored at Palmer. Morris (2014) reported that the "wax" dropped out of the fuel during the cold months and formed a thick layer at the bottom of the fuel tank that subsequently had to be shoveled out. Since then, the MGO has been replaced with Antarctic Diesel (reported gel point of $-4.4^{\circ} \mathrm{C}$ ). Though the gel point of the Antarctic Diesel is not much lower than the MGO's, Antarctic Diesel is reported by Morris (2014) to be working well at Palmer Station for the intended application of that fuel. Based on this experience, though J P-8 has a FP below the reported storage temperature of

\footnotetext{
* While Morris (2014) uses the word "wax," the make-up of this substance is not known; but it is likely crystalized fuel that has a wax-like texture.
} 
the bulk of the fuel at South Pole, the fact that J P-8's FP is very close to the storage temperature, and owing to the uncertainty in the actual temperature in the fuel arches, it is prudent to thoroughly document fuel storage temperature at South Pole and consider possible freezing of pipelines as part of the evaluation of the feasibility of using alternate fuels at South Pole. Freezing of the fuel in storage tanks or fuel lines at South Pole could have catastrophic consequences during the winter months.

Figure 5. Comparison of statistics of the observed air temperature at South Pole Station to the FP specification for candidate aircraft fuels.

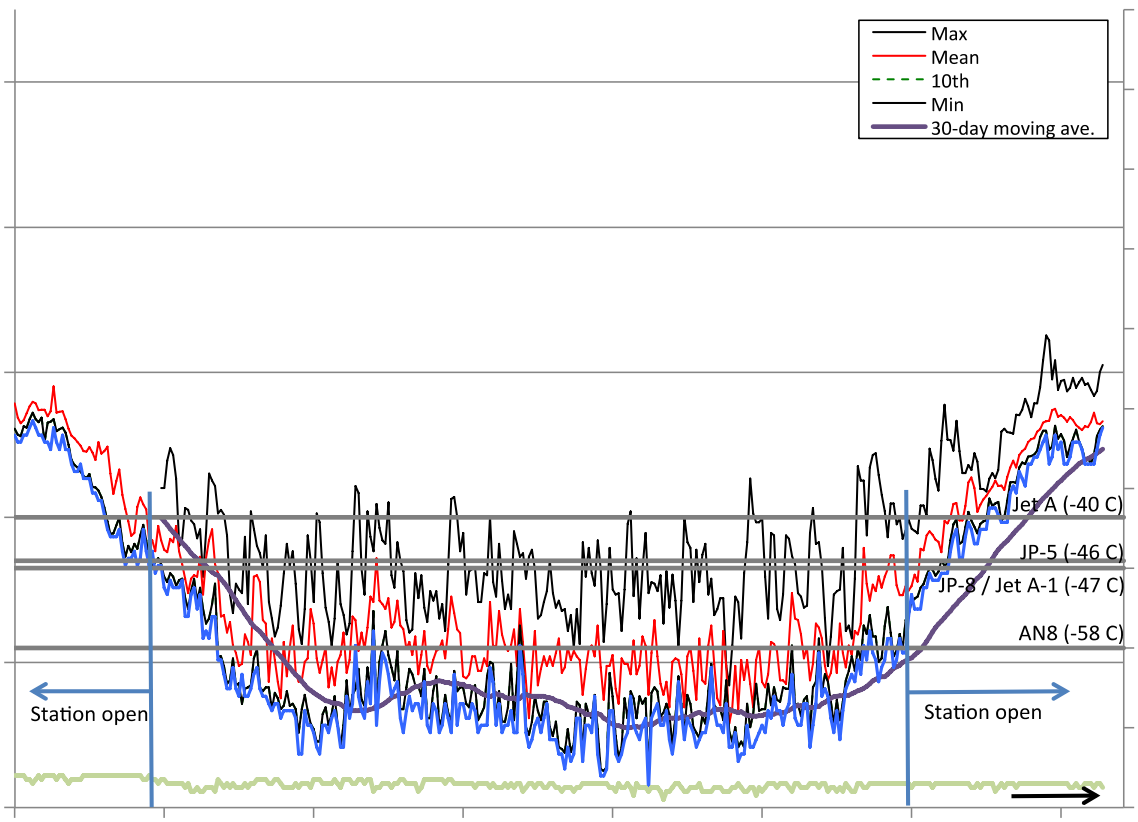

Figure 6 makes a similar comparison for the WAIS Divide camp. As noted previously, we lack enough data at WAIS Divide to make a direct comparison; and Figure 6 provides an estimate of the lower envelope of the temperature data at WAIS based on data observed at Byrd Station (approximately 100 miles away).

Like South Pole, WAIS Divide sees much lower temperatures than McMurdo, with average minimum daily air temperatures reaching to or below the FP specification for all of the identified fuels; the fuel is stored in 10,000 gal. bladders at WAIS. However, there are no operations at WAIS Divide during the winter; the fuel is only stored at that location during winter. Provided the fuel temperature as a whole is above the FP specification before it is required, it should be available for use, provided there is 
no stratification or separation of the fuel due to freezing and thawing that may compromise its use. Fuel separation could occur if a higher density fuel compound (i.e., higher density than the bulk fuel) freezes before the bulk of the fuel freezes. If this is the case, the high density, high freezing temperature component would settle to the bottom of the tank or bladder. Because this substance is on the bottom of the tank, it will remain in close contact with the cold ground and thaw out last. The air temperature and solar radiation will heat the top of the storage container faster, thawing first the less dense contents of the fuel that float to the top of the vessel. In this circumstance, such fuels may remain stratified for a long time after thawing unless the contents are remixed by an agitator or other mixing device. We note that remixing fuel stored in a bladder may not be a trivial endeavor, and remixing can happen only once the entire contents have melted.

Figure 6. Comparison of estimated statistics of air temperature at WAIS Divide camp (based on temperature data obtained from Byrd Station [Appendix A]) to the freeze temperature specification for candidate aircraft fuels.

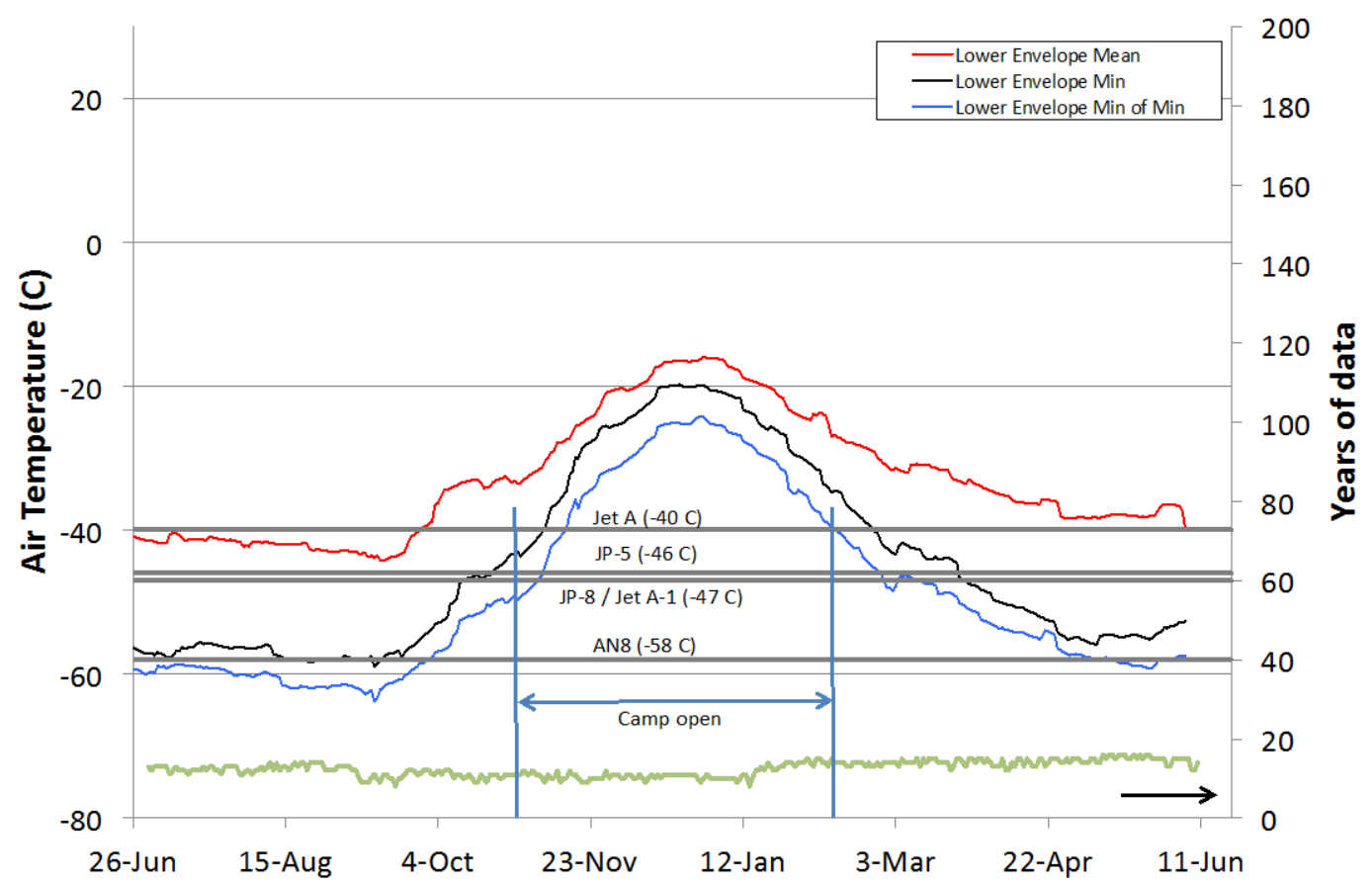

On the other hand, if compounds that freeze first are less dense than the bulk, these will have a tendency to float on the top of the fuel when they freeze. Because this frozen portion of the fuel is on the top of the tank, it will be in the warmest part of the tank when the sun and higher spring air temperatures start to reheat the vessel and its contents. This will enable 
the entire mass of the fuel to thaw out faster, reducing the chance for persistent stratification and separation of the fuel. To accelerate the remixing process, it still may still be advisable to provide capability for agitating or mixing fuel that will undergo a planned freezing cycle.

For the fuels that might be used by the USAP, what is the likelihood of its separating during freezing; and would we expect the higher freezing temperature component to sink or float within the remaining fuel mixture? Table 2 can help answer these questions, assuming that mixing these fluids together does not affect the freezing temperature of any single component. Though not comprehensive, Table 2 identifies many of the components that commonly appear in aviation fuel. Obviously, any compounds that freeze at a higher temperature than the FP specification are likely to be removed from the fuel or altered through further refining. Therefore, what we would expect to remain in any significant quantity are compounds that have a freeze point below the specification*. Table 2 identifies all compounds that have a freezing temperature lower than the FP for J P-8 (highlighted either red or blue). Compounds that have a freezing temperature lower than the FP of AN8 are highlighted blue. We note that the reported bulk density of J P-8 is 775- $840 \mathrm{~kg} / \mathrm{m}^{3}$ (ExxonMobil Aviation 2005). Therefore, we would expect any compound that freezes and has a density lower than J P-8 would float on top when it freezes and that any compounds denser would sink.

There are only two compounds highlighted in Table 2 that are denser than the reported bulk density of J P-8: toluene and $\mathrm{m}$-xylene. Of these two compounds, $\mathrm{m}$-xylene has a freezing temperature very close to that of the FP for J P-8. Therefore, we can expect this compound to settle to the bottom of the J P-8 fuel when it freezes. Toluene has a freezing temperature of $-95^{\circ} \mathrm{C}$; and therefore, we do not expect it to freeze at all, even in the lowest temperatures expected at WAIS. The paraffins and olefins that we would expect to freeze first (octane, nonane, and undecene) would separate out and float to the top. Thus, we would expect some stratification when J P-8 reaches the expected FP. This may be manageable as most of

\footnotetext{
* The material safety data sheet (MSDS) sheets for JP-8, frequently report naphthalene as a constituent of the fuel though the reported concentration of naphthalene is $0.04 \%$ or less by weight. Though naphthalene has a freezing temperature of $80.3^{\circ} \mathrm{C}$, it appears to be generally present in such a small quantity as not to affect the low-temperature performance of the fuel.
} 
the components that have a freeze point higher than the FP specification are less dense than the bulk fuel and should float to the top.

Comparing the operational season to the fuel specifications, the only fuel that has a FP above the estimated average air temperature during the operational season is J et A. This suggests that all of the fuels except J et A may be used at WAIS during the operational season, at least for groundbased applications. However, we will want to consider this further before we conclusively say fuels other than AN8 would perform adequately. For example, in a batch of fuel used in the field, the proportion, or even the presence, of any one these components highlighted in Table 2 is typically not published by the manufacturer as it can vary widely from one batch to the next. Therefore, we recommend that remixing and reusability of the fuel when subjected to a cold quench cycle as depicted by Figure 5 be tested before approving the use of an alternate fuel at WAIS Divide or at any other location where freezing of all or any portion of the fuel will occur during storage.

In Figure 6, we obtained an estimated lower air temperature envelope based on a centered 30-day running average of the daily reported values. This means that the running average comes from the average observed data 15 days before and 15 days after the day of interest. This is adequate for obtaining an estimate of the air temperature but not for the fuel temperature stored in a large tank. As previously discussed, a large fuel bladder (e.g., 10,000 gal. as is used at WAIS) may take 20 days or longer to equilibrate to the air temperature. As such, the fuel temperature will lag the air temperature by 20 or more days, depending on the capacity of the bladder.

To obtain an estimate of the fuel temperature in storage at WAIS Divide, we created a 20-day running average using only preceding data (i.e., not a centered average). This should provide a more accurate picture of when the fuel temperature is warm enough to use at camp opening. Figure 7 presents the result of this computation. Here, we compare only the running average of minimum average daily air temperature. This shows that only the stored AN8 and J P-8 would be warm enough to use at the start of the operational season, with the fuel temperature of J P- 5 staying above the FP about 10 days after the start of the operational season. 
Figure 7. Comparison of the estimated minimum fuel temperature at WAIS Divide camp to the freeze temperature specification for candidate aircraft fuels. This estimate is based on temperature data obtained from Byrd Station (Appendix A) and applying a 20-day running average to the data, assuming that is takes approximately 20 days for the stored fuel to equilibrate with the air temperature.

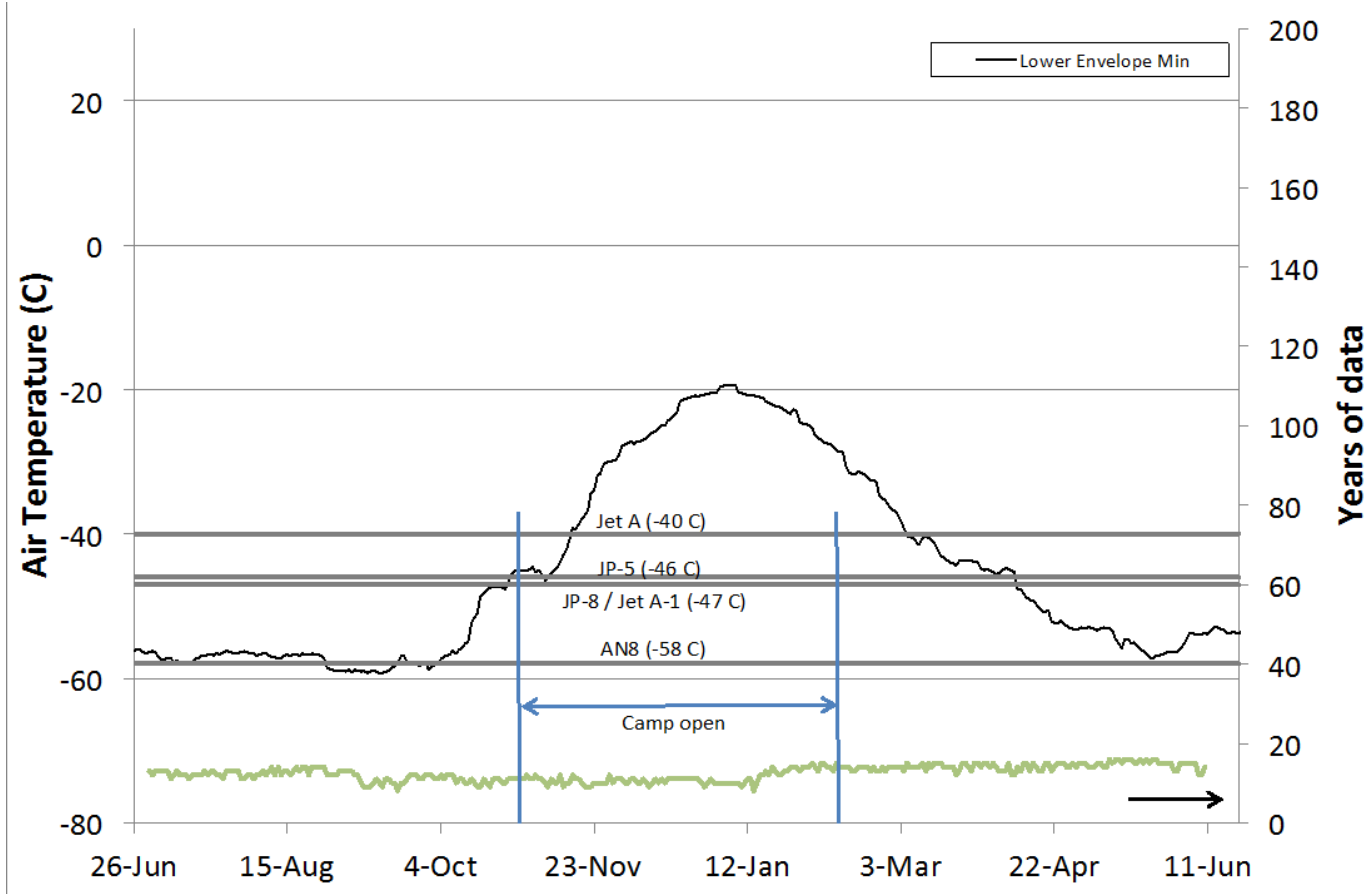

From the review and analysis provided in this section, standardization to a single fuel type for ground-based applications may be primarily dependent on the WAIS Divide camp. Though the air temperatures at South Pole are much colder than at WAIS Divide, fuel storage at South Pole is more protected from the environment; and the temperature in the fuel arches is generally around $-45^{\circ} \mathrm{C}$ during the winter months. So, at South Pole, the chance of fuel freezing is lower than at WAIS. Yet, at WAIS Divide, the fuel is stored outside throughout the winter months; and the estimated temperature of the stored fuel rises above $-47^{\circ} \mathrm{C}$ (the FP specification of JP-8) just before the camp opens. We note that the temperature of the stored fuel rises above $-46^{\circ} \mathrm{C}$ (the FP specification for J P-5) at approximately the same time; but based on the temperature estimate, the fuel temperature dips to just below this specification soon after the camp opens. This suggests that J P- 5 may be acceptable within the uncertainty of the estimated fuel temperature given in Figure 7. If stratification and separation of the fuel during the freezing and thaw process does not pose a significant performance problem for the J P- 5 or the JP-8 fuels, it appears that AN8, J P-8, and J P-5 may perform satisfactorily at all of the sites iden- 
tified. However, as J P-5 is classified as an "alternate," fuel and not a "recommended" fuel for the LC-130, fuels that could potentially be used for both ground and aviation applications would need to be restricted to AN8 and J P-8. 


\section{Fuel Compatibility for Air Applications}

In the previous section, we concentrated on fuel compatibility for groundbased applications. For that analysis, the temperature at the ground is an acceptable indicator of the extreme temperatures that operations may encounter. Yet, for air operations, the temperature at flight altitude is much colder than at the surface. For LC-130 flight operations, the NYANG determines the estimated air temperature at flight elevation over the departure and destination locations to verify that it is warm enough to fly, considering the FP of the fuel they are using (Herdrick 2013b). We use that same approach to determine the effects in a change in fuel type on flight operations.

To estimate air temperature aloft, we use the standard atmosphere temperature lapse rate $\left(-2^{\circ} \mathrm{C} / 1000 \mathrm{ft}\right.$ of altitude) to estimate the change in air temperature from the ground level at each station to flight altitude. Table 4 provides the altitude of each of these stations. The typical flight level for travel is between 18,000 and 27,000 ft above MSL (mean sea level) (Herdrick 2013b). Pilots will maintain the lower flight altitude as necessary to keep within the temperature specifications of the fuel type they are using (Herdrick 2013b); therefore, we will use the lower flight level to estimate the anticipated air temperature during flight as follows:

$$
T_{a d j}=(18000 \mathrm{ft}-\text { station elevation }) / 1000 \times \text { lapse rate }
$$

where the lapse rate is $-2^{\circ} \mathrm{C} / 1000 \mathrm{ft}$ as stated above. Table 5 provides this calculation for each station.

Table 5. Estimated drop in air temperature at the indicated flight altitudes near three locations in Antarctica.

\begin{tabular}{|l|c|}
\hline \multicolumn{1}{|c|}{ Location } & $\begin{array}{c}\text { Temperature adjustment, } T_{\text {adj }}\left({ }^{\circ} \mathrm{C}\right), \\
\text { at 18,000 ft flight altitude }\end{array}$ \\
\hline McMurdo & -34 \\
\hline South Pole & -15 \\
\hline WAIS Divide & -23 \\
\hline
\end{tabular}

For flight operations, this adjustment is applied to the departure and destination locations to estimate if the air temperature will be warm enough to support operations. We apply this to the temperature data presented in 
section 4 to obtain an estimated temperature at flight altitudes for each of these stations, as shown in Figures 8- 10.

Figure 8 shows that at the minimum flight level $(18,000 \mathrm{ft})$, the mean air temperature near McMurdo is below the FP of AN8 at WINFLY (the winter fly-in of equipment, etc.). J ust before station open, the mean air temperature rises just above the AN8 FP. However, at WINFLY and for some time after station opening, the estimated minimum average air temperatures is well below the FP of AN8. On the other end of the season (near station close), the estimated minimum air temperatures do not drop below the FP until just before station close. It is interesting to reiterate that the fuel supplied at Christchurch is J et A-1; so, mid-winter MEDEVAC and WINFLY missions use J et A-1 to fly into McMurdo even though the air temperature at the flight level is well below the $-47^{\circ} \mathrm{C}$ FP specification. If these winter flights require a refuel before departure from McMurdo, they are fueled with the AN8 stored at McMurdo airfields during the winter.

We observe from Figure 9 that at South Pole, the estimated mean and minimum average air temperatures at 18,000 ft are also below the FP specification for AN8 for a short period right after station open. J ust before station close, it is only the minimum average temperature at $18,000 \mathrm{ft}$ that drops below the FP of AN8.

Figure 8. Estimated temperature at $18,000 \mathrm{ft}$ altitude at McMurdo, Antarctica.

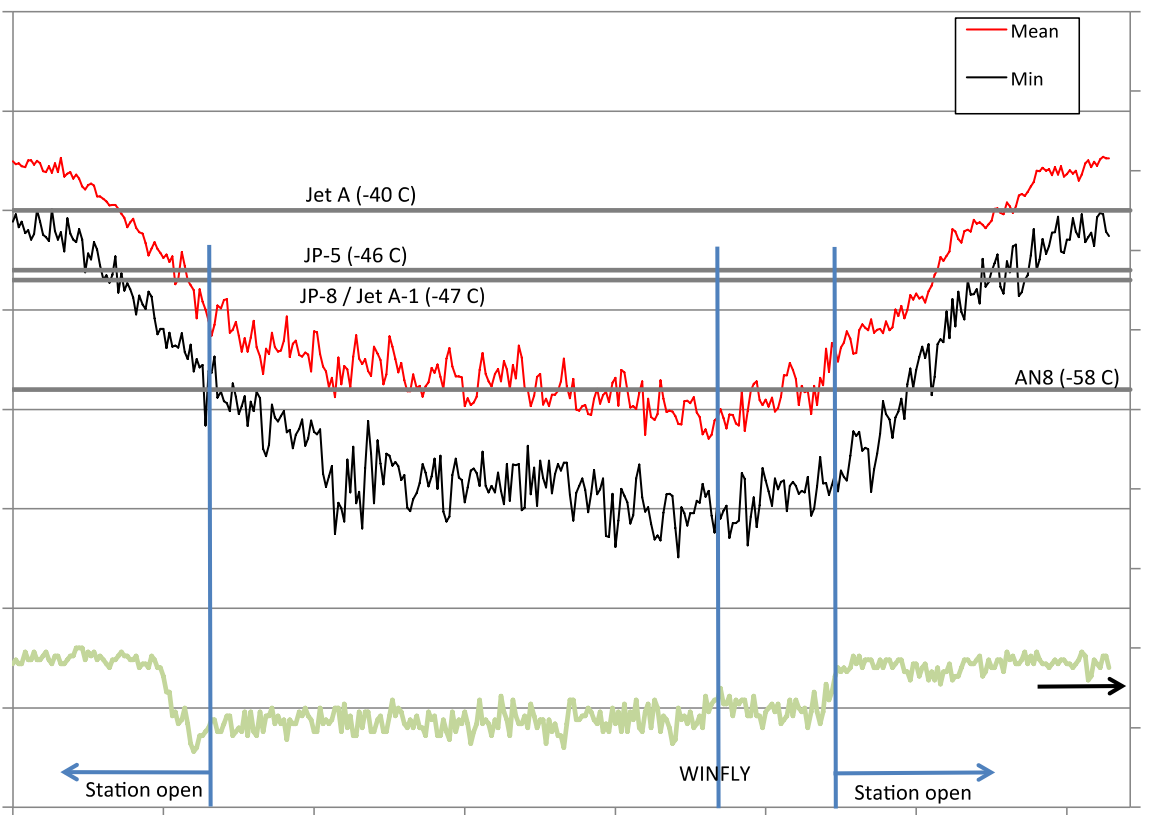


Figure 9. Estimated temperature at $18,000 \mathrm{ft}$ altitude at South Pole Station.

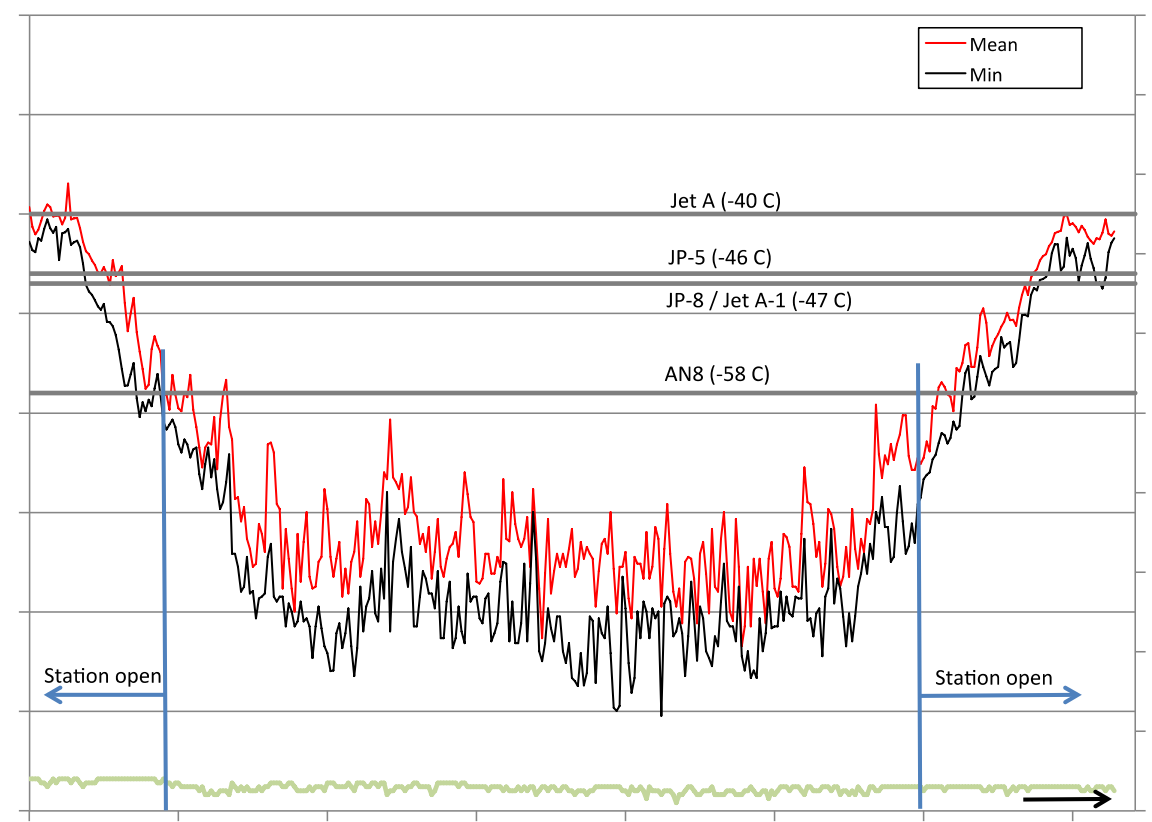

Figure 10. Estimated temperature at $18,000 \mathrm{ft}$ altitude at WAIS Divide camp.

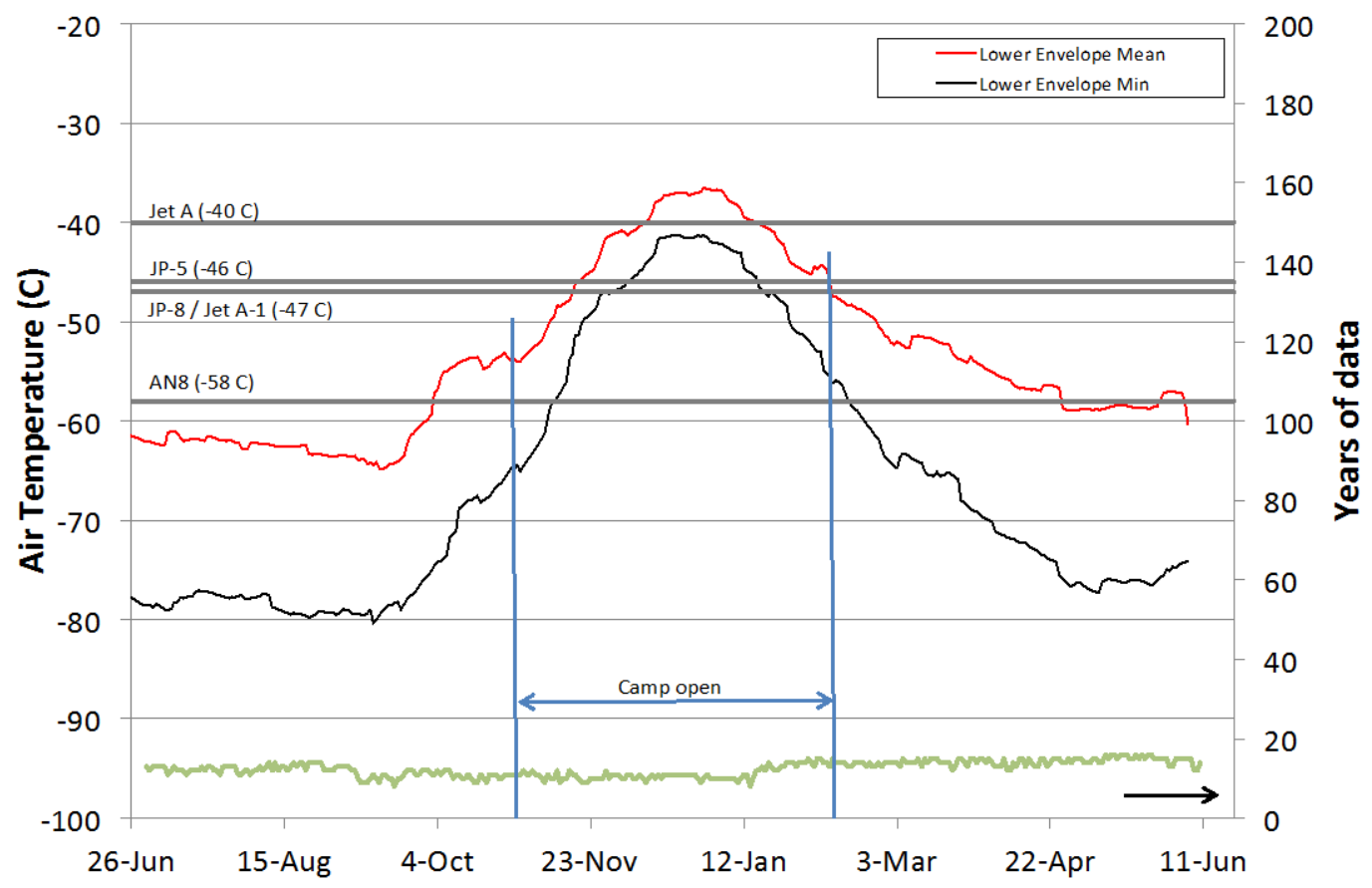

At the WAIS Divide camp, the estimated mean air temperature (Figure 10) at the flight level remains above the FP of AN8 during that camp's entire 
operational season; yet the estimated average daily minimum temperature is below the FP for a short period following camp open.

Low temperatures during the operational window of McMurdo, South Pole Station, or camps (including WAIS Divide) have on occasion caused flight cancellations. In these situations, opening of South Pole may be delayed and/ or the station may close earlier than planned due to low temperatures (Herdrick 2013c). Therefore, we would expect that use of an alternate fuel (e.g., J P-8) might narrow the operational window at these sites. To illustrate, in Table 6 we show the approximate current open and close dates for these three sites and compare them to the potential changes in the open and close dates if USAP depended on using only J P-8 fuel. At a minimum, this would place a heavier demand on a ground-based resupply for South Pole Station (i.e., the South Pole Operations Traverse [SPoT]) to replace the reduced number of days that aircraft could fly supplies into South Pole. There would be a similar need to emphasize resupply and transport of equipment and materials to McMurdo by vessel to offset the reduced number of flying days. Additionally, it would be necessary to review whether the required science personnel could be transported in and out during the reduced time windows given in Table 6.

Table 6. The current opening and closing dates at McMurdo, South Pole, and WAIS Divide compared to the approximate required start and end dates of air operations at the same sites if JP-8 were used.

\begin{tabular}{|l|c|c|c|c|c|c|c|c|c|}
\hline & \multicolumn{3}{|c|}{ Normal Season (AN8) } & \multicolumn{3}{c|}{$\begin{array}{c}\text { Min. Average Daily } \\
\text { Temperature }\end{array}$} & \multicolumn{3}{c|}{ Mean Daily Temperature } \\
\hline & & & & $\begin{array}{c}\text { Goes } \\
\text { Above } \\
\text { Location }\end{array}$ & $\begin{array}{c}\text { Drops } \\
\text { Below } \\
\text { Open-8 FP }\end{array}$ & $\begin{array}{c}\text { Days } \\
\text { Above } \\
\text { FP }\end{array}$ & $\begin{array}{c}\text { Goes } \\
\text { Above } \\
\text { JP-8 FP }\end{array}$ & $\begin{array}{c}\text { Drops } \\
\text { Below } \\
\text { JP-8 FP }\end{array}$ & $\begin{array}{c}\text { Days } \\
\text { Above } \\
\text { FP }\end{array}$ \\
\hline McMurdo & 1 Oct. & 23 Feb. & 145 & 17 Nov. & 5 Feb. & 80 & 1 Nov. & 27 Feb. & 118 \\
\hline South Pole & 27 Oct. & 15 Feb. & 111 & 3 Dec. & 20 Jan. & 48 & 1 Dec. & 2 Feb. & 63 \\
\hline WAIS Divide & 27 Oct. & 8 Feb. & 105 & 26 Nov. & 17 Jan. & 52 & 15 Nov. & 10 Feb. & 87 \\
\hline
\end{tabular}

From Table 6, we see that, depending on what criterion is used (historical minimum average, daily temperature, or mean daily temperature trends), changing the fuel type can cut the operating season in half (minimum average daily) or reduce it by about 20\% (mean daily) at McMurdo and WAIS Divide. Using either criterion, these are significant reductions, especially at South Pole ( $57 \%$ and $43 \%$ reductions, respectively). If J P-8 is to replace AN8, it will be important to seriously consider whether the required work and air-based resupply can be completed at these locations in the shortened timeframe. 
We do not know the rationale behind the NYANG selecting as its flying limit the aloft air temperature at which the fuel type being used has a published FP. However, this limit is clearly very conservative as frictional heating of the wings during flight is well known and will act to keep the onboard fuel warmer than the outside air temperature. Additionally, the rate of fuel cooling is not considered, and for the relatively short flight durations between McMurdo and on-continent locations, one could argue that there is not sufficient cold exposure time aloft to generate adequate cooling down to the fuel's FP even when ignoring the frictional heating of the wings. Further, all aircraft types that depart Christchurch for McMurdo are fueled with J et A-1. With an 8-hour flight duration for the LC-130, for much of the operating season, it is very likely the aloft temperature at some point during the flight is lower than the $-47^{\circ} \mathrm{C} \mathrm{FP}$ of the fuel. This includes C-17 flights during the austral winter, when even ground temperatures at McMurdo are not far about the FP of J et A-1. Yet, we do not know of any fuel freezing troubles over the several decades of missions flown for USAP. In fact, commercial aircraft throughout the world use J et A for fuel; and when flying at 38,000 ft-a typical cruising altitude for aircraft-if the ground temperature is at $20^{\circ} \mathrm{C}$ (room temperature), the estimated temperature at cruising altitude would be $-56^{\circ} \mathrm{C}$, well below the FP of $-40^{\circ} \mathrm{C}$ for J et $\mathrm{A}$.

Still, considering the low ground temperatures in Antarctica, the paucity of alternate landing locations, and the lack of robust ground support at every USAP airfield, any ground delay (e.g., weather hold or mechanical issue) could easily cause severe cold soaking of the aircraft and its fuel. If this caused thickening of the fuel, it could result in a massive effort (perhaps spanning more than one austral summer season) to remove the aircraft from the site. Thus, having a conservative approach, such as the NYANG have, is prudent. However, calculations should be performed and discussion held to ascertain if any lesser degree of conservatism is acceptable.

The comparison in Table 6 does not consider C-17 operations supporting mid-winter scheduled and MEDEVAC operations or the annual WINFLY at McMurdo in late August as they are outside of the operating season. Any consideration of not having AN8 available at McMurdo will need a thorough review of the effects of refueling these flights with J P-8 before adopting it as an acceptable practice. 
A related issue is refueling of the Kenn Borek Air (KBA) aircraft that use caches of fuel in the field and refuel at South Pole in mid-October and late February en route to and from McMurdo. The KBA aircraft tend to operate at lower temperatures and more remote locations than LC-130s and may depend more heavily on the low-temperature properties of AN8 (Morris 2015b). 


\section{Proposed Options for Analysis}

Based on the above data, we recommend analysis of the following possible options to determining the cost and feasibility of adopting alternative fuels for use in USAP:

1. Retain AN8 for all applications that currently use AN8 (baseline condition). This option would be used to establish baseline costs only.

2. Do away with JP-5 and use only mogas and AN8. (Icebreaker fuel would be brought down by vessel and directly transferred from the vessel to the icebreaker.)

3. Store AN8 at McMurdo for WINFLY and mid-winter scheduled flights and MEDEVAC operations and in emergency tanks at South Pole (100,000 gal.). For all other uses of AN8, replace with eitherJ P-5 or J P-8. (Note: J P-5 cannot be used for aviation as it is considered and "alternate" fuel for that application.)

a. Assume all of AN8 at WAIS is replaced with J P-8.

b. Assume all of AN8 at McMurdo is replaced with J P-8 or J P-5.

c. Assume all of AN8 at South Pole is replaced by J P-8. (It would be necessary to consider heating requirements for external tanks and external equipment that runs through the winter.)

4. Use AN8 for flight operations only. All ground assets would useJ P-5 or JP-8.

A follow-on effort should be conducted to provide the analysis of the feasibility and potential cost savings of these options. 


\section{Conclusions and Recommendations}

In this report, we reviewed how the fuel ordering and delivery process and the temperature records at three locations (McMurdo, South Pole, and WAIS Divide camp) in Antarctica to determine if options for cost savings exist and the feasibility of using alternative fuels to AN8 for ground and flight applications. The ability to have increased flexibility in the fuel delivery schedule could result in savings for NSF. This analysis also shows that, at all three sites, it may be possible to use J P-8 for ground applications (generators, heating, heavy equipment, etc.) during the summer season and at McMurdo. At South Pole, the bulk of the fuel is stored in subsurface unheated shelters where the temperature is maintained around $-45^{\circ} \mathrm{C}$ all year, above the $-47^{\circ} \mathrm{C}$ FP of J P-8. So, for the most part, use of JP-8 at South Pole may not detrimentally affect operations, provided heat tracing of external piping and other provisions are made to accommodate this "warmer" fuel. However, small quantities of fuel are stored in tanks outside at South Pole; for these applications, it may be necessary to heat the tanks during portions of the year if J P-8 is adopted. Furthermore, equipment that needs to be operated year-round (e.g., dozers) may require tank heaters and additional cold-weather modifications to ensure reliable operation using J P-8. Also, the fuel and air temperature within the fuel storage arches at South Pole is not monitored currently. We recommend that if conversion to use of J P-8 at South Pole becomes a serious consideration, that a fuel and air temperature monitoring system be installed in the fuel arches to verify the actual temperature through the year. Further analysis as outlined in section 5 is required to determine if the cost savings of the fuel is enough of an offset to cover increased costs associated with tank and fuel line heaters needed to maintain safe operations at South Pole.

During the winter months, we expect the temperature of the stored fuel at WAIS Divide camp to drop below the FP of J P-8. This means at least a portion of the fuel would solidify, and some level of density separation may take place. However, our analysis shows that the fuel temperature should be above the freeze point before camp opens. Therefore, storage of J P-8 through the winter may not affect using the fuel during the operational season. Yet, experience has shown that remixing the solidified fuel with the bulk is required to keep heavy paraffins that have settled to the bottom from remaining there and concentrating over time. Remixing the fuel in the bladders currently used for storage at WAIS may be difficult. In 
addition to being a surrogate for all of the other USAP camps on the Antarctic continent, this initial temperature analysis at WAIS also provides insight into the usability of fuel caches stored on continent to support KBA transits as well. If these fuel caches will be restocked with J P-8 in place of AN8, a more thorough review of the timing when those caches will be used needs to be conducted.

We note that for flight operations, the air temperature at flight altitudes will drop below the FP of J P-8 during a significant portion of the summer season at McMurdo, South Pole, and WAIS Divide. Sole use of J P-8 for flight operations into these locations could have the net effect of shortening the operational season by as much as $57 \%$ (South Pole). However, the reduction in operational season length at other locations (McMurdo and WAIS Divide) may be as little as 20\%. Further review of the guidance for determining flight limits based on fuel FP is warranted as the above analysis does not take into account frictional heating of the wings that prevents freezing of the fuel during flight.

To better understand the potential cost savings and performance tradeoffs, we recommend conducting a cost- benefit analysis of the use of J P-8 versus AN8 for the scenarios outlined in section 5. This analysis would allow a greater understanding of the potential savings realized by using lessexpensive fuels. The study would also include the negative offsets, including the additional hardware and alterations (tank and fuel line heaters, separate storage tanks, etc.) and other operational costs required for the fuel changeover and provide a basis for deciding the best course of action with respect to fuel usage in USAP. 


\section{References}

ASTM. 2010. Standard Test Method for Filterability of Diesel Fuels by LowTemperature Flow Test (LTFT). ASTM D4539-10. West Conshohocken, PA: ASTM International.

— 2012. Standard Test Method for the Freezing Point of Aviation Fuels. ASTM D2386-06. West Conshohocken, PA: ASTM International.

Christchurch International Airport Limited. 2012. Z Energy Limited - Aviation. Christchurch Airport. Christchurch, New Zealand: Christchurch Airport. http://www.christchurchairport.co.nz/en/airport-information/airport-campus-directory/zenergy-limited-aviation/.

ExxonMobil Aviation. 2005. World J et Fuel Specifications with AvGas Supplement. 2005 edition. Leatherhead, UK: ExxonMobile Aviation.

Platts. 2017. About S\&P Global Platts. http://www.platts.com/about.

Hadaller, O. J ., and J . M. J ohnson. 2006. World Fuel Sampling Program. CRC Report No. 647. Alpharetta, GA: Coordinating Research Council, Inc.

Herdrick, B. 2013a. Email communication. 4 December. Scotia, NY: U.S. Air Force, Air National Guard, 109OSF/OPA, Antarctic Operations.

—. 2013b. Email communication. 5 December. Scotia, NY: U.S. Air Force, Air National Guard, 109OSF/OPA, Antarctic Operations.

—. 2013c. Email communication. 12 December. Scotia, NY: U.S. Air Force, Air National Guard, 109OSF/ OPA, Antarctic Operations.

IPCS (International Programme on Chemical Safety). 1998. Kerosene. Material Safety Data Sheet CAS \#8008-20-6. International Programme on Chemical Safety.

Knuth, M. 2014. Other Country Fuel Facts AHM input.xlsx. Excel spreadsheet. 20 November. Arlington, VA: National Science Foundation, Division of Polar Programs.

Morris, A. 2015a. Email communication. 21 April. Centennial, CO: Antarctic Support Contractor.

— 2015b. Personal communication. 19 May. Centennial, CO: Antarctic Support Contractor.

_ 2014. Email communication. 24 November. Centennial, CO: Antarctic Support Contractor.

Zabarnick, S., and J . Ervin. 2010. The Effects of Operating J et Fuels Below the Specification Freeze Point Temperature Limit. DOT/ FAA/AR-09/50. Washington, DC: U.S. Department of Transportation, Federal Aviation Administration, Office of Research and Technology Development. 
Zabarnick, S., Z. J. West, L. M. Shafer, and R. Cook. 2013. Studies of the Scanning Brookfield Viscometry as a Replacement for Freezing Point in Aviation Fuel Specifications. CRC Project No. AV-16-11. Alpharetta, GA: Coordinating Research Council, Inc. 


\section{Appendix A: Estimate of Temperature Data for WAIS Divide Camp Using Data from Byrd Station*}

Though meteorological data for the WAIS Divide camp is available since 2006, the quality is minimal until 2009. Starting in 2009, hourly data is available for the operational season. Table A- 1 shows the start and end of the data records starting in 2009. Unfortunately, this limited amount of data is insufficient to determine statistics for WAIS Divide. To get an estimate of the climatology at WAIS Divide camp, we obtained data from the next nearest continuously recording meteorological station, which is located at Byrd Station about 100 miles away. A global summary of the day (GSOD) data for this site was available from NCDC dating back to 10 May 1990. We note, however, that there are gaps in the data and that there are only about 15 years of data in this 23-year record.

Table A-1. WAIS Divide temperature record duration based on meteorological data obtained from the Antarctic Meteorological Research Center.

\begin{tabular}{|c|c|c|c|}
\hline Year & Start & End & Days \\
\hline $2008-09$ & 1 Jan. 2009 & 7 Feb. 2009 & 38 \\
\hline $2009-10$ & 10 Nov. 2009 & 5 Feb. 2010 & 88 \\
\hline $2010-11$ & 8 Nov. 2010 & 8 Feb. 2011 & 93 \\
\hline $2011-12$ & 5 Nov. 2011 & 3 Feb. 2012 & 91 \\
\hline $2012-13$ & 27 Oct. 2012 & 8 Feb. 2013 & 105 \\
\hline
\end{tabular}

To determine if the data at Byrd was a reasonable surrogate for the WAIS Divide camp, we computed the daily statistics (average, maximum, and minimum daily temperatures) for WAIS Divide and compared that to the same information on the same day recorded at Byrd Station. There were 304 days where there was an overlap of data. Figures A-1 to A-3 compare data for both sites. We obtained from each comparison a least squares fit to an equation of the form,

$$
T(\text { WAIS })=b+T(\text { Byrd }),
$$

\footnotetext{
* Appendix by Robert Haehnel and John Gagnon, ERDC-CRREL.
} 
where $\mathrm{T}$ is the air temperature. The y-intercept, $\mathrm{b}$, computed from the curve fit is the offset between the two data sets. We found that, on average, the temperature at WAIS Divide camp was a few degrees colder than Byrd Station. Table A-2 summarizes the results of this comparison. The coefficient of determination, $\mathrm{R}$, for the average and minimum temperatures is above 0.8 though it is not as good for the maximum temperature: $\mathrm{R}=0.589$. Yet, we are not concerned with maximum temperatures; it is the minimum temperatures that determine operability. Based on the comparison, we conclude that the data obtained at Byrd is a reasonable surrogate for WAIS Divide, provided the offsets in Table A-2 are applied to the data.

Table A-2. Computed temperature offsets between Byrd Station and WAIS Divide camp obtained from Figs. A-1 through A-3.

\begin{tabular}{|l|c|c|}
\hline Temperature Statistic & Offset, $b\left({ }^{\circ} \mathrm{C}\right)$ & Coefficient of Determination, $\boldsymbol{R}$ \\
\hline Average & -2.42 & 0.867 \\
\hline Maximum & -3.06 & 0.589 \\
\hline Minimum & -1.58 & 0.807 \\
\hline
\end{tabular}

Owing to the noise in the data obtained at Byrd, we did not consider it prudent to simply apply the offsets to that data to estimate the temperature at WAIS Divide camp. What is of most interest is the lower bounding envelope of the data. To determine this, we smoothed the data using a running average as follows:

Running average $=$ Centered average $( \pm 15$ Days $)-(\operatorname{Max}[ \pm 15$ Days $]-\operatorname{Min}[ \pm 15$ Days $]) / m$

with $\mathrm{m}=3$ for the minimum of the daily average data and the minimum of the daily minimum data while $\mathrm{m}=2$ for the average of the daily average data. Figure A-4 indicates the lower envelope computed for each of these cases. This was used as an estimate of the lower temperature bound for Byrd Station. To determine the lower temperature bound for WAIS Divide, we shifted these bounds by $-2.42^{\circ} \mathrm{C}$ (Figure A-1) for the average of the daily average data and by $-1.58^{\circ} \mathrm{C}$ (Figure A-3) for the minimum bounds. We used this approach to estimate the temperature variation at the WAIS Divide camp for the alternate fuel study. This provides a conservative lower bound for the temperature data at WAIS Divide. 
Figure A-1. Comparison of average daily air temperatures between Byrd Station and WAIS Divide camp. This shows that the average daily temperature is on average $-2.42^{\circ} \mathrm{C}$ lower at WAIS than at Byrd. This comparison is for temperature data obtained for the WAIS Divide camp operational season (approximately November through early February). The total number of points is $n=304$.

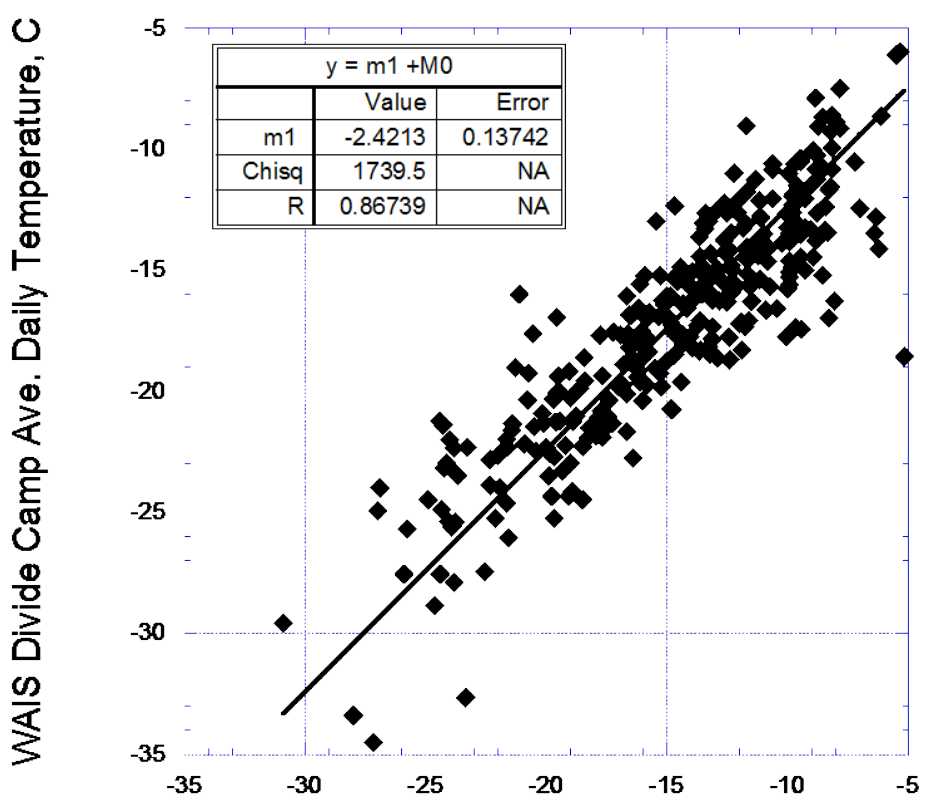

Byrd Station Ave. Daily Temperature, C

Figure A-2. Comparison of maximum daily air temperatures between Byrd Station and WAIS Divide camp. This shows that the maximum daily temperature is on average $-3.06^{\circ} \mathrm{C}$ lower at WAIS than at Byrd. This comparison is for temperature data obtained for the WAIS Divide camp operational season (approximately November through early February). The total number of points is $n=304$.

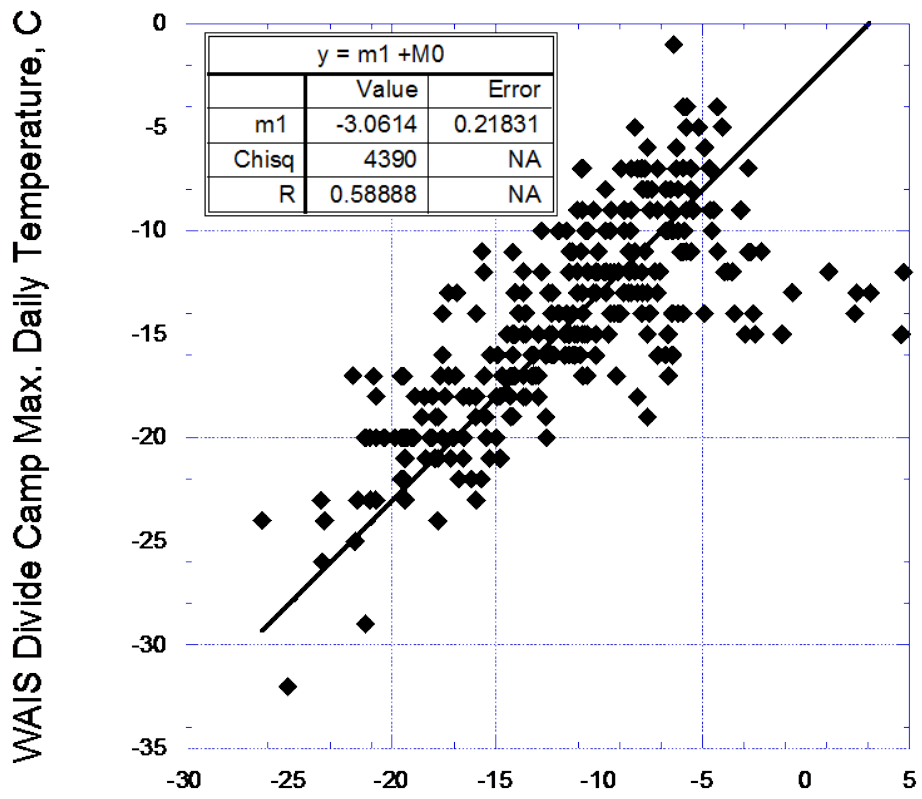

Byrd Station Max. Daily Temperature, C 
Figure A-3. Comparison of the minimum daily air temperatures between Byrd Station and WAIS Divide camp. This shows that the minimum daily temperature is on average $-1.58^{\circ} \mathrm{C}$ lower at WAIS than at Byrd. This comparison is for temperature data obtained for the WAIS Divide camp operational season (approximately November through early February). The total number of points is $n=304$.

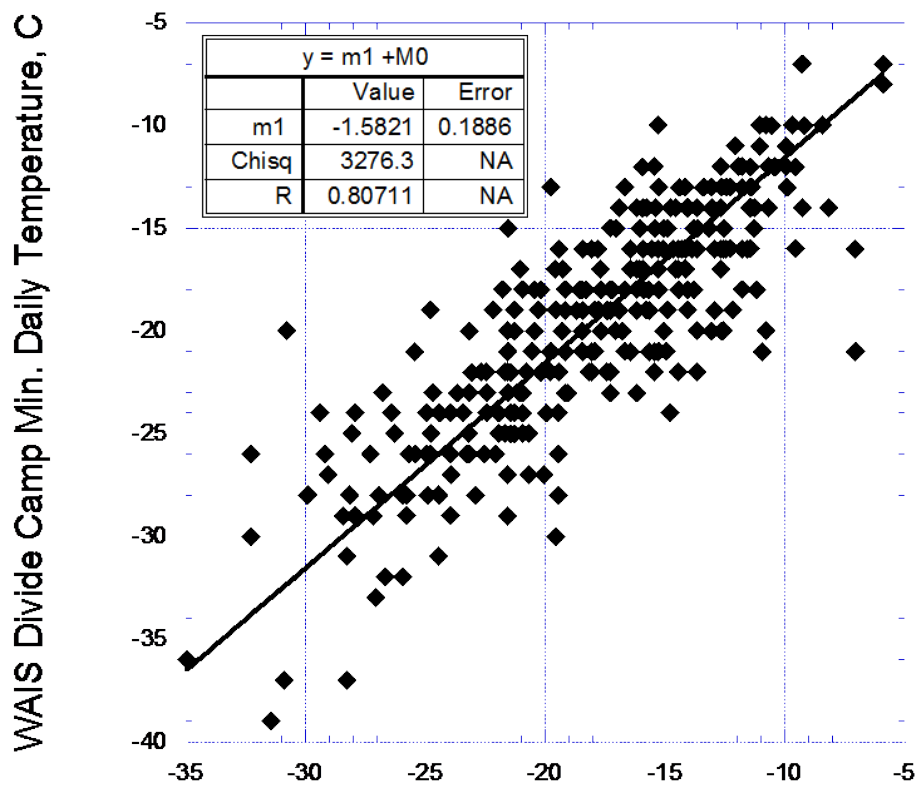

Byrd Station Min. Daily Temperature, C

Figure A-4. Determination of the lower envelope of air temperature data obtained at Byrd Station, Antarctica. The lower envelop is a smoothing of the data via a 30-

day running average.

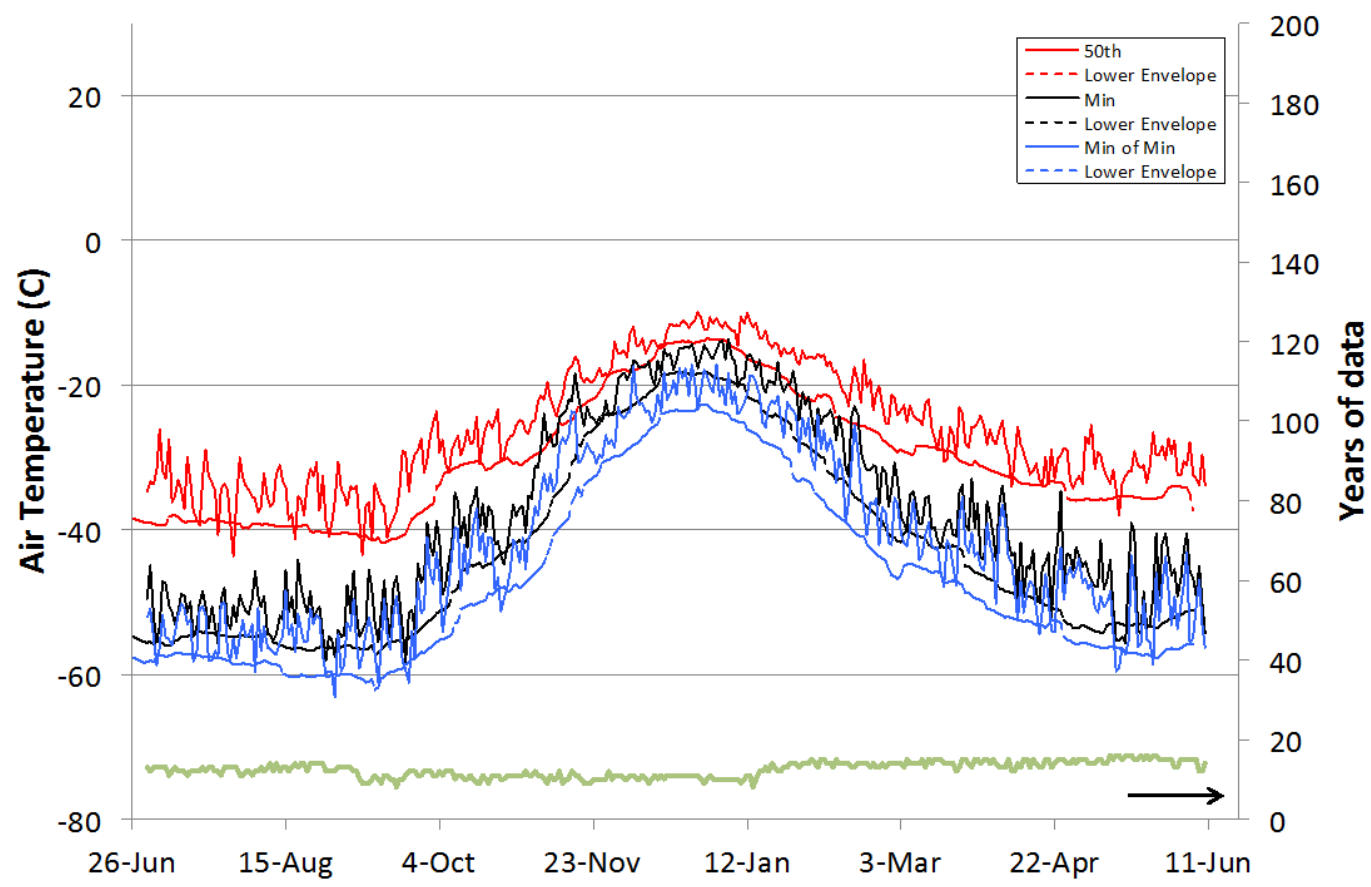




\section{REPORT DOCUMENTATION PAGE}

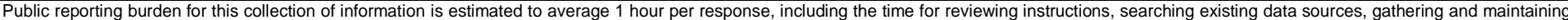

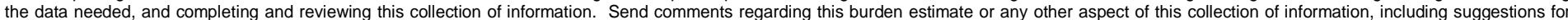

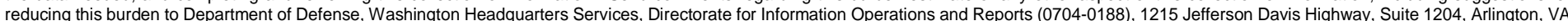

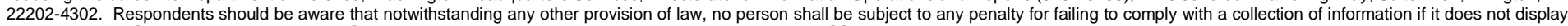
a currently valid OMB control number. PLEASE DO NOT RETURN YOUR FORM TO THE ABOVE ADDRESS.
1. REPORT DATE (DD-MM-YYYY)
2. REPORT TYPE
September 2017
Technical Report/Final

\section{TITLE AND SUBTITLE}

Feasibility of Using Alternate Fuels in the U.S. Antarctic Program: Initial Assessment

Feasibility of Using Altente Fuels in the U.S. Antarctic Program: Initial Assessment

\section{AUTHOR(S)}

Robert B. Haehnel, Terry Melendy, and George L. Blaisdell

3. DATES COVERED (From - To)

5a. CONTRACT NUMBER

5b. GRANT NUMBER

5c. PROGRAM ELEMENT NUMBER

5d. PROJECT NUMBER

5e. TASK NUMBER

EP-ANT-14-23

5f. WORK UNIT NUMBER

7. PERFORMING ORGANIZATION NAME(S) AND ADDRESS(ES)

8. PERFORMING ORGANIZATION REPORT NUMBER

U.S. Army Engineer Research and Development Center (ERDC)

Cold Regions Research and Engineering Laboratory (CRREL)

ERDC/CRREL TR-17-15

72 Lyme Road

Hanover, NH 03755-1290

9. SPONSORING I MONITORING AGENCY NAME(S) AND ADDRESS(ES)

10. SPONSOR/MONITOR'S ACRONYM(S)

NSF

National Science Foundation, Office of Polar Programs,

Arlington, VA 22230

11. SPONSOR/MONITOR'S REPORT NUMBER(S)

\section{DISTRIBUTION / AVAILABILITY STATEMENT}

Approved for public release; distribution is unlimited.

\section{SUPPLEMENTARY NOTES}

Engineering for Polar Operations, Logistics, and Research (EPOLAR)

\section{ABSTRACT}

Currently, the U.S. Antarctic Program (USAP) has standardized using AN8 fuel for all air operations and the majority of its ground based operations. The freeze-point (FP) specification for AN8 is $-58^{\circ} \mathrm{C}$. The U.S. Army Cold Regions Research and Engineering Laboratory (CRREL) conducted an analysis of the air temperature history at McMurdo, South Pole, and the WAIS (West Antarctic Ice Sheet) Divide camp to determine if USAP could feasibly use alternate, less expensive aircraft fuels. Also, to provide context, this report details the USAP fuel purchasing methodology and price calculation.

JP-8 (and Jet A-1) has an FP specification of $-47^{\circ} \mathrm{C}$, which is well below the minimum average daily air temperature at McMurdo $\left(-40^{\circ} \mathrm{C}\right)$ and is also below the storage temperature of the fuel at South Pole $\left(-45^{\circ} \mathrm{C}\right)$. The estimated fuel temperature at the WAIS Divide camp is above the FP of JP-8 during the operational season. Based on these findings, it may be possible to use JP-8 to replace ground-based applications where AN8 is currently used. Evidence suggests that JP-8 can replace the AN8 used for all flight operations, also.

\section{SUBJECT TERMS}

Airplanes--Fuel, Antarctic, Aviation, Cold temperature, EPOLAR, Fuel, Ground applications, Logistics, NSF

\section{SECURITY CLASSIFICATION OF:}

\section{a. REPORT}

Unclassified

\section{b. ABSTRACT}

Unclassified

\section{c. THIS PAGE}

Unclassified
17. LIMITATION OF ABSTRACT

SAR
18. NUMBER OF PAGES

52 19a. NAME OF RESPONSIBLE PERSON

19b. TELEPHONE NUMBER (include area code) 